University of Louisville

ThinkIR: The University of Louisville's Institutional Repository

Electronic Theses and Dissertations

$5-2020$

\title{
Predictors of binge drinking among military veterans: a general strain theory approach.
}

\author{
Emily Ann Hayden \\ University of Louisville
}

Follow this and additional works at: https://ir.library.louisville.edu/etd

Part of the Criminology and Criminal Justice Commons, and the Military and Veterans Studies Commons

\section{Recommended Citation}

Hayden, Emily Ann, "Predictors of binge drinking among military veterans: a general strain theory approach." (2020). Electronic Theses and Dissertations. Paper 3421.

https://doi.org/10.18297/etd/3421

This Doctoral Dissertation is brought to you for free and open access by ThinkIR: The University of Louisville's Institutional Repository. It has been accepted for inclusion in Electronic Theses and Dissertations by an authorized administrator of ThinkIR: The University of Louisville's Institutional Repository. This title appears here courtesy of the author, who has retained all other copyrights. For more information, please contact thinkir@louisville.edu. 


\title{
PREDICTORS OF BINGE DRINKING AMONG MILITARY VETERANS: A
}

\section{GENERAL STRAIN THEORY APPROACH}

\author{
By \\ Emily Ann Hayden \\ B. S., Kentucky Wesleyan College, 2013 \\ M. A., Eastern Kentucky University, 2015
}

\begin{abstract}
A Dissertation
Submitted to the Faculty of the

In Partial Fulfillment of the Requirements

for the Degree of

Doctor of Philosophy

In Criminal Justice

Department of Criminal Justice

University of Louisville

Louisville, Kentucky
\end{abstract}

College of Arts and Sciences of the University of Louisville

May 2020 
Copyright 2020 by Emily Ann Hayden

All rights reserved 

PREDICTORS OF BINGE DRINKING AMONG MILITARY VETERANS: A GENERAL STRAIN THEORY APPROACH

$$
\text { By }
$$

\author{
Emily Ann Hayden \\ B. S., Kentucky Wesleyan College, 2013 \\ M. A., Eastern Kentucky University, 2015 \\ A Dissertation Approved on
}

April 16, 2020

By the following Dissertation Committee:

Dr. George E. Higgins

Dr. Gennaro Vito

Dr. Viviana Andreescu

Dr. Cathy Marcum 


\section{DEDICATION}

This dissertation is dedicated to my parents

\section{Mrs. Cheryl Ann Morris}

and

Mr. Larry Dale Hayden

who have given me invaluable educational opportunities. 


\section{ACKNOWLEDGEMENTS}

I would like to thank Dr. George Higgins and express unrelenting gratitude for his expertise, patience and guidance throughout this process. Thank you Dr. Higgins for being there for me every step of the way. I would also like to thank my dissertation committee members, Dr. Gennaro Vito, Dr. Viviana Andreescu and Dr. Cathy Marcum for their comments, guidance and support.

I would like to thank my sister, Melanie Hayden for encouraging me throughout this entire process. Without her knowledge, help and unwavering faith in me I never would have made it this far. I would like to extend my sincerest gratitude to my employers and co-workers at Campbellsville University for believing in me and working with me while I completed my dissertation. Without their unwavering support, encouragement and grace through my first year of teaching, completing this dissertation would not have been possible. 


\title{
ABSTRACT \\ THE EFFECTS OF BINGE DRINKING AMONG MILITARY VETERANS: A GENERAL STRAIN THEORY APPROACH
}

\author{
Emily A. Hayden
}

April 16, 2020

This dissertation is theoretically informed by General Strain Theory (GST) (Agnew 1992, 2002), and examines binge drinking within a military veteran population. It begins with an assessment on reform and focuses on shaping knowledge around the issue of binge drinking by military veterans. The current study uses Agnew's GST to argue for an understanding of how strain and stress can affect individuals who have served in the military and acknowledges how this strain can lead to negative coping mechanisms such as binge drinking. The latter part of the dissertation argues that understanding Agnew's GST $(1992,2002)$ with a military population can help implement better knowledge and treatment for our United States military veteran population.

The dissertation is divided into five parts, covering binge drinking issues, how that problem of binge drinking pertains to military veterans, theory, practice, and implementation for change. Chapters one and two provide insight on the problem of binge drinking as well as the scope of the problem for military veterans. Chapter three focuses on bringing together theory and how it can shed light on the problem with binge drinking in military veterans. Chapters four, five and six discuss the methodology of the 
data from the National Survey on Drug Use and Health, the analysis and the discussion on how this problem can be addressed.

Keywords: military, general strain theory, depression, binge-drinking 


\section{TABLE OF CONTENTS}

ACKNOWLEDGEMENTS ........................................................................... iv

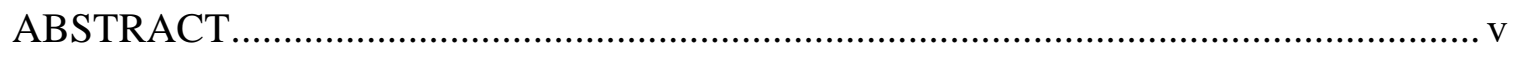

LIST OF TABLES .......................................................................................... viii

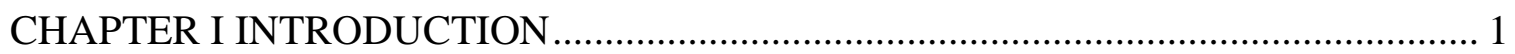

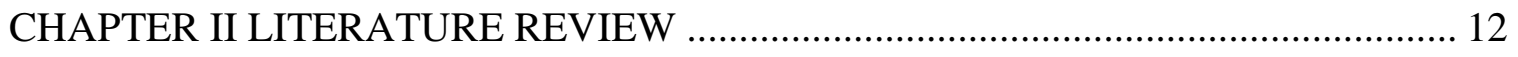

CHAPTER III THEORETICAL FRAMEWORK .................................................. 24

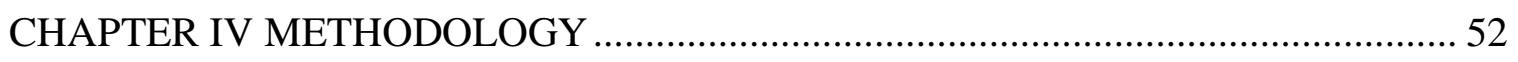

National Survey of Drug Use and Health (2015-2017)........................................................52

The Current Study: Binge drinking issues in veterans ..........................................................55

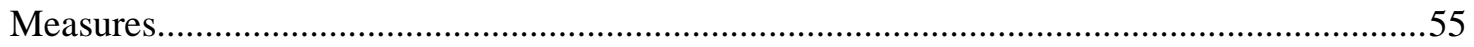

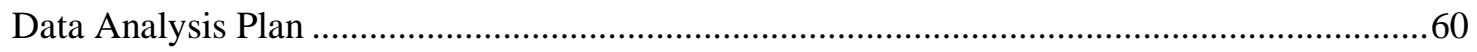

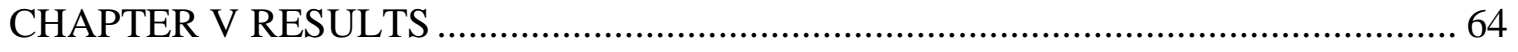

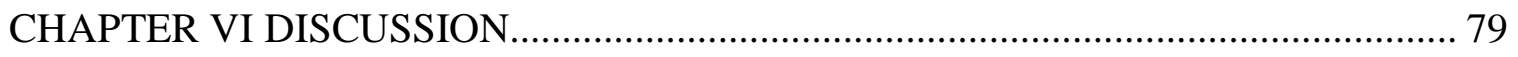

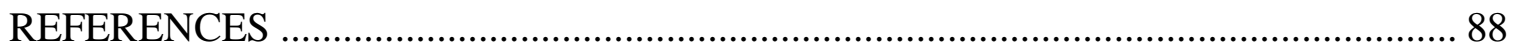

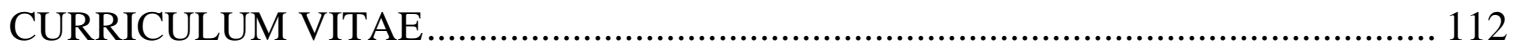




\section{LIST OF TABLES}

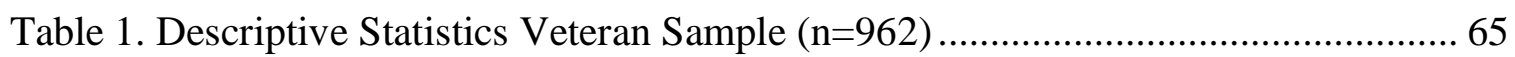

Table 2: Bivariate Correlations between Variables in the Veteran Sample $(n=962) \ldots \ldots . . .68$

Table 3: Binomial Logistic Regression Analysis for Veterans ................................... 70

Table 4. Descriptive Statistics Veteran with Combat Sample $(n=453)$.......................... 72

Table 5: Bivariate Correlations between Variables in the Combat Veteran Sample

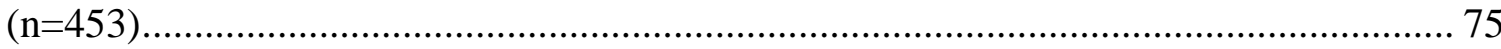

Table 6: Binomial Logistic Regression Analysis for Combat Veterans ......................... 77 


\section{LIST OF FIGURES}

Figure 1: Line Graph Binge Drinking in Veterans (n=962).......................................... 66

Figure 2: Line Graph Binge Drinking in Veterans with Combat Exposure $(n=453)$...... 73 


\section{CHAPTER I}

\section{INTRODUCTION}

Military veterans have been an understudied population in regard to the research literature. There is also a lack of literature regarding binge drinking in military veterans. As a group, they have been overlooked in terms of binge drinking due to the perception of the toughness mentality that is associated with being in the military (Bucher, 2011). Historically, drug and alcohol usage have been prevalent in the military population, especially during wartime for decades. The drug of choice is dependent on time and location of the war.

Historically, substances that were used in the 1860s are different than the substances that are available today. Ultimately, this could explain where veterans' drug/alcohol of choice may have started. Drug and alcohol use to cope with what occurred while in a military environment is not a new phenomenon. Literature has shown that substances have been used during wartime for decades (Buchanan, 1992; Stanton, 2009).

\section{Historical overview of drug use in the military}

The Civil War (1861-1865) was the first documented instance of drug addiction for military service. During the American Civil War, morphine was viewed as a wonder drug, often used as a painkiller and anesthetic. An estimate of 400,000 soldiers returned 
home addicted to morphine (Golub \& Bennett, 2013). In the Civil War a term was created called the "soldiers' disease," in reference to soldiers' morphine addictions (Courtwright, 2001). World War I, known as the Great War, occurred in 1914 to 1918. World War I has often been called The Tobacco War by historians (Springfield, 1902). The government had provided cigarettes to soldiers to help reduce stress. However, during this time cocaine had become the drug of abuse on the frontlines. Soldiers used cocaine to boost energy and combat fatigue and anxiety (Rasmussen, 2011).

During World War II, amphetamines became the drug of choice and soldiers accounted for the largest number of amphetamine users from 1939 to 1945 . An early version of crystal meth, called Pervitin, was patented in 1937 and marketed for military use. Pervitin was issued to soldiers to combat fatigue, boost energy and enhance performance. During this time the Pentagon issued just short of 500 million Benzedrine (amphetamine) tablets to the U.S. troops during wartime as 15\% of American soldiers took the drug on a regular basis (Rasmussen, 2011).

During the Vietnam War (1955-1975), servicemen increasingly used marijuana. This was followed by the influx of heroin or opium in 1970s (Robins et al., 1975). The influx of heroin resulted in one-fifth of enlisted troops returning from war with addiction (Stanton, 2009). According to Bray et al., (2009), marijuana is the most widely used illicit drug for active duty soldiers since the early 1980s.

There is a complex political, sociological, psychological, and biological relationship between warfare and drugs. This begins with the shift in attitudes about drug use. Buchanan (1992) demonstrates that drug taking habits are embedded in social 
dynamics where drug use is prohibited or inhibited. Buchanan (1992) discusses how our country has a love-hate relationship with drug use and identifies three cycles marked by major conflicts: the American Revolution, the Civil War, and Vietnam and the civil rights era. Research has found that after each of these major crises, drug use increased, followed by phases of public disapproval.

What substance soldiers initially use during their military service often follows them as they become compulsive users in civilian life (Anthony et al., 1994). Compulsive substance use is defined as "a pattern of drug consumption that is stimulus bound stereotyped, difficult to regular and identified by a loss of control over intake" (Tiffany \& Carter, 1998, p. 1). Compulsive substance use is often due to combat experiences, trauma and other types of stress, bringing us to the current problem of binge drinking among military veterans. Research found that the most recent wartime conflicts in Iraq and Afghanistan resulted in increased alcohol consumption and binge drinking (Bray et al., 2009).

\section{Current Problem: Binge Drinking}

The misuse of alcohol and drugs is prevalent in the United States military today. According to a 2008 Survey of Health-Related Behaviors, half of active duty military reported binge drinking with a $35 \%$ increase in a decade. Binge drinking behaviors are even higher for soldiers who experienced combat (Bray et al., 2007). Binge drinking is common in Operation Enduring Freedom (OEF) and Operation Iraqi Freedom (OIF) veterans (Killgore et al., 2008). Veterans often binge drink as a way to numb the pain and erase the memories that resurface from their service during wartime. 
Research has found that greater combat exposure and human trauma is associated with binge drinking among OEF/OIF veterans (Killgore et al., 2008). The heavy alcohol use is often a way to self-medicate (Jacobson et al., 2008). There are several reasons that contribute to the misuse of drugs and alcohol in today's military veterans, such as traumatic brain injury, combat and post-traumatic stress disorder (PTSD). Soldiers who suffer traumatic brain injuries are more likely to develop alcohol problems (Golub \& Bennett, 2013). Binge drinking among military veterans can cause an array of issues for the veterans and have unintended consequences on their families (Gibbs et al., 2007).

\section{Effects of Binge Drinking in Military Veterans}

Alcohol, drugs and war have a long history of association. Alcohol and drugs served the purpose to prepare soldiers for battle, facilitate cultural bonding and to cope with the physical and emotional aftermath of the war (Bergen-Cico, 2012). Bray \& Hourani (2007) found that frequent heavy drinking has increased from 15 to $20 \%$ between 1980 and 2005. Rates of heavy drinking were also dependent on the military service branch. Individuals in the Army, Navy and Marines were more frequent in binge drinking than the Air Force. Issues with drinking occur in veterans exposed to combat-related traumatic stress and stressful military experiences (Schumm \& Chard, 2012).

There are many unintended consequences that military life has on families of soldiers. Research has found that children of deployed soldiers have an overall rate of child maltreatment that is $42 \%$ greater during deployment (Gibbs et al., 2007). Research indicated that children of soldiers during deployment described increases in anxiety and depression (Jensen et al., 1989; Lester et al., 2010). Rosen et al. (1993), found that 
families of deployed soldiers demonstrated less cohesiveness than non-deployed families. Children with a parent who is deployed reported posttraumatic symptoms and were more likely to demonstrate externalizing behaviors (Lester et al. 2010).

Deployment was associated with marital instability and impaired family function.

Research found that young children in families that have a military parent are affected by deployment, had social emotional risk, such as increased psychological health symptoms including anxiety, emotional distress and behavioral problems. They also had greater peer problems and decreased prosocial behaviors (Lester, et al., 2010). Research found that there were significant associations between frequent binge drinking and age, gender, race, marital status, and having a dependent child in the home (Calhoun et al., 2016). Income, military unit type, and traumatic events during deployment were also associated with binge drinking (Calhoun et al., 2016).

\section{The Current Study}

The purpose of this dissertation is to investigate binge drinking issues in military veterans with a GST lens. Specifically, the goal of this dissertation is to determine how strenuous war experiences and difficulties adapting to civilian life such as finding employment can affect binge drinking among military veterans. Are veterans more likely to have binge drinking issues as a result of their experiences in the military? How does strain affect depression for military veterans? Finally, what kind of treatment options are in place to provide support for military veterans?

Research has rarely used GST to examine binge drinking using samples from military veteran populations. This dissertation addresses this void in the literature by 
utilizing a partial test of Agnew's GST among a sample of military veterans from the National Survey of Drug Use and Health (NSDUH) 2015-2017 data. GST is an appropriate theoretical framework when examining binge drinking because Agnew describes strains or stressors as events or conditions that are disliked by individuals. In sum, strains can result from a person losing positive stimuli, receiving negative stimuli, or failing to achieve positively valued goals. The basis of GST is that the reason individuals engage in crime and deviance is to alleviate stress that was caused by a strain and the negative emotional affect that is related to the strain.

There is an array of effects that the misuse of substances such as alcohol has on the military. Binge drinking can affect military force readiness, suicidal ideation, mental health issues, emotional distress, anxiety, depression and environmental stress (Bray \& Hourani, 2007). The abuse of substance, such as binge drinking, can cause bipolar, depression, anxiety, psychotic and some other psychiatric disorders which results in a need for diagnosis and treatment and can negatively affect service members and their performance (Sharbafchi \& Heydari, 2017). There are several health problems that have been linked to heavy alcohol use which include liver damage, cancers, cardiovascular disease, and injuries, such as motor vehicular crashes, falls, drowning and burns (CDC, 2019). This heavy use has been shown to also be associated with major depression (Room, Babor \& Rehm, 2005; McKenzie et al., 2006).

GST is an appropriate theoretical perspective to explain binge drinking issues within the military veteran population due to its unique lens on the effect strain and stressors have on individuals. Including the negative emotional response to frustration 
can aid in explaining how individuals in the military turn to alcohol and drugs. This theoretical perspective can help explain the current study's research questions on how soldiers' experiences in the military can lead to binge drinking issues, including depression. Agnew's 2006 theoretical perspective can also aid the current study in suggesting appropriate treatment options available to veterans from the GST lens.

The current study will make several contributions to the literature. First, it examines an understudied demographic group within the GST literature. This will test the generalizability of GST among military veterans. GST has been applied to the military in other research. However, analyzing binge drinking by military veterans through a GST lens has been understudied. For example, Calhoun et al., (2016) examined binge drinking among U.S. veterans in Iraq and Afghanistan. Bucher (2011) examined coping behaviors in a sample of Army personnel, and self-reported offending of substance use, violence and theft.

Another significant study by Hoopsick et al. (2017) utilized data from the National Survey of Drug Use and Health (NSDUH). The authors examined substance use and dependence issues in a retired military population. The results indicating that those who separated/retired from the military have a higher likelihood of substance use/dependence than current reserve members. Trautmann et al. (2014) examined 1,483 soldiers who were deployed to Afghanistan and found that substance use and mental disorders are associated with recently deployed soldiers.

While these studies are important in terms of advancing the GST literature, they had noteworthy limitations that the current study intends to overcome. One recurring 
limitation was that their data was cross-sectional in nature, which did not allow for causal references to be made (Hoopsick et al., 2017; Trautmann et al., 2014). Another limitation for several of the studies were the small sample sizes and analysis groups that prevented the results from being generalized (Bucher, 2011; Trautmann et al., 2014). A noteworthy limitation is the limited number of predictors through the independent, dependent and control variables that were military-specific factors (Hoopsick et al., 2017). Calhoun et al., (2016) did not utilize a theoretical orientation in explaining binge drinking behaviors in veterans. Also, Trautmann et al.'s (2014) findings only apply to the definition of use patterns that were presented in their research, which were the DSM-5 criteria of alcohol abuse, alcohol dependence and nicotine dependence.

The current study addresses these limitations by being able to use a national dataset, resulting in larger sample sizes to provide more accurate generalization of the results. The data is nationally representative with probability sampling providing an estimate of drug use and health related behaviors. The National Survey on Drug Use and Health (NSDUH) also examines criminal justice involvement among civilians and military in the United States among individuals over 12 years old. The survey tracks trends in alcohol, tobacco and various other drugs and assesses consequences while also identifying these groups at high risk for substance use and misuse. However, the current data will also utilize the NSDUH dataset, which still limits the selection of independent, dependent and control variables, making it difficult to overcome the limitations of Hoopsick et al's 2017 study. The NSDUH also has several missing cases within their dataset. 


\section{Contribution}

The current study addresses these voids in the literature and seeks to advance the knowledge on understanding the reasons that binge drinking issues are so high within the military culture. The current dissertation intends to examine whether strains result in depression and whether depression results in binge drinking behaviors. This will allow further insight in causes or correlates that are most conducive to addressing binge drinking issues within the military. More specifically, what types of strain result in depression in military veterans?

The current study answers these questions by examining different types of environmental factors for military veterans such as combat, marital status, health, housing stability and employment. There are multiple measures available to examine a proxy of strain including measures of depression, binge drinking DSM-5, combat, employment, and income. Some studies have found connections between depression and the military and substance use and the military. However, few studies have connected military with GST, depression and binge drinking issues as emotional coping strategies, like alcohol use, drug use is used to "terminate, reduce, or escape from the strainful events and conditions" (Agnew, 2001, p. 326).

Providing explanations of binge drinking by military veterans from a GST perspective will contribute to the literature as this is a topic that is rarely researched from this lens. The intention of the current dissertation is to inform policy and practice as they relate to improving the quality of life among military veterans. For example, the findings could provide insight into the types of services that could benefit military veterans. 
Services could include better treatment options for individuals with binge drinking problems as well as problems with depression. It would be informative to practitioners to know how services may vary based on the type of treatment that military veterans need.

Furthermore, information that ties in factors culturally relevant to military veterans could be used to inform administrators and executives of government agencies. Information could lead to veteran affairs in distributing where funding is needed to allocate the most appropriate resources to community programs and activities that involve military and veterans. Community organizations that offer services to military veterans and families of military who may have binge drinking issues could be implemented. Specific programs tailored to military veterans could include stress management, anger management, health and wellness, and relapse prevention among others.

In addition, the current study's findings could inform policy that would lead to implementation of programs to improve outcomes for military veterans who have problems with binge drinking. Policy and programs could consider the specific needs for military veterans. For example, promoting health connection to family members and providing information on PTSD, and potential substance issues to military veterans and family. Specifically, programs taking a holistic approach have been found to better increase the likelihood of successful reintegration into civilian life (Golub, Vazan, Bennett, \& Liberty, 2013; White, Barber, Azrael, Mukamal, \& Miller, 2011).

This dissertation is separated into several chapters. Chapter 2 provides a detailed overview of the research literature as it relates to military and binge drinking. Chapter 3 
will provide an overview of GST and its essential arguments that relate to the current study. The research hypotheses and the study's analytic model will be addressed in this chapter.

Chapter 4 introduces the methodology used to examine the hypotheses that are provided in the previous chapter. A description of the sample, measures and analytic plan are discussed. Following the discussion of the methodology, chapter 5 provides expected results of the analysis with a series of tables, including the logistic regression analysis. Finally, chapter 6 discusses anticipated findings that are reported in chapter 5 within the context of the research literature outlined in chapters 2 and 3. 


\section{CHAPTER II}

\section{LITERATURE REVIEW}

The current study tests the assumption that individuals experience different types of strain, which produces negative emotional affects, such as depression. Then, the pressures and negative emotions of strain are alleviated by committing crime and deviancy (Agnew, 1992, 2006). The focus of this chapter is to review the research literature as it specifically relates to the participants of this study - military veterans and their involvement in binge drinking behaviors. First, the chapter begins with a general discussion of binge drinking issues for those in the military, how they came about, and how policy tried to alleviate the issue.

\section{Military Veterans}

According to Zogas (2017), "When service members become veterans, they exit an institution which trained them in very specific skills, behaviors, and values" (p. 4). A veteran is defined as "a person who served in the active military, naval or air service, and was discharged or released under conditions other than dishonorable" (38 CFR 3.1(d)). According to the U.S. Census, there are 18.2 million veterans in the United States. One negative aspect military veteran's is that they often witnessed and participated in grueling activities while enlisted. 
Veterans witness several acts during their time served that could all relate to binge drinking issues. For example, veterans who witness combat and war may cause substantial amount of trauma. Having witnessed trauma can cause veterans to have several issues from PTSD and mental health issues to substance issues (Friedman, Schnurr, \& McDonagh-Coyle, 1994). The instability of civilian life may also be a significant source of stress, from unstable home lives or marriages to PTSD or depression and may result in binge drinking (Calhoun et al., 2016).

\section{Binge Drinking}

According to the National Institute of Alcohol Abuse and Alcoholism (2004), binge drinking “is a pattern of drinking that brings a person's blood alcohol concentration (BAC) to 0.08 grams percent or above" (p.1). The amount of alcohol consumed that defines binge drinking is different for men and women. Male binge drinking is defined as consuming five or more drinks while women's binge drinking is consuming four or more drinks in 2 hours (National Institute of Alcohol Abuse and Alcoholism, 2004). Binge drinking is also associated with a number of health problems.

Several health problems include unintentional injuries such as car crashes and alcohol poisoning, violence, sexually transmitted diseases, unintended pregnancy, chronic diseases such as high blood pressure, stroke and heart disease (CDC, 2019). Binge drinking can also cause cancers of the breast, mouth, throat, esophagus, liver and colon, as well as memory and learning problems and alcohol dependence (CDC, 2019). Binge drinking has been referred to as episodic drinking and linked to a range of health and 
psychological problems (Bradley et al., 2001). Not only is binge drinking associated with health problems, it is also costly.

Binge drinking cost the United States an estimated of \$191 billion in 2010. Costs resulting from losses in workplace productivity, health care, criminal justice and other expenses (Sacks et al., 2015). According to SAMSHA, binge drinking can increase an individual's risk of alcohol use disorder. One major contributor to binge drinking is the historical variation in social roles that are associated with binge drinking such as marriage, parenthood, college attendance and employment status (Bachman et al., 2002). The National Epidemiologic Survey on Alcohol and Related Conditions (NESARC) estimated a 38\% increase in binge drinking from 2002 to 2013 . The most substantial increase in binge drinking was found in those between the ages of 30 to 49 , with higher binge drinking in women in the 1956-1960 birth cohort (Grucza et al., 2018). Binge drinking can also be associated with depression. A recent study of young adults between the ages of 18 and 30 looked at depression and binge drinking behaviors and found that young adults with a depressive disorder that participate in comorbid drinking are associated with poorer neuropsychological outcomes. Those who had depression and engaged in binge drinking performed worse in visual learning and memory tasks (Hermens et al., 2013).

\section{Binge Drinking Among Military Veterans}


Military veterans face disproportionate levels of strain that make them an interesting population to study within the context of GST. For example, with respect to on-the-job strain, researchers found that more than one-quarter $(27.4 \%)$ of their sample of 1,173 U.S. Armed Forces personnel who attended suicide prevention training reported suffering from significant job stress and depression with both being significantly related to one another. Even though $45 \%$ reported symptoms of depression, less than $7 \%$ of their sample were receiving mental health care. The authors found that "work stress was significantly and positively correlated with symptoms of depression" (Pflanz \& Ogle, 2006, p. 862).

Research by Calhoun et al., (2016), examined excessive binge drinking in veterans and found it is a growing concern for veterans who returned from service in Iraq and Afghanistan. The results showed, "Any binge drinking was reported by $51 \%$ of the sample" (p. 272). An earlier study by the same authors indicated that binge drinking was prevalent among $23 \%$ of OEF/OIF veterans who were using Veteran Affairs services. Among their sample of $500 \mathrm{OIF} / \mathrm{OEF}$ veterans, binge drinking was primarily associated with younger age men and single status (Calhoun et al., 2008).

Binge drinking was also found to be associated with younger, male soldiers who experienced combat and PTSD (Jacobson et al., 2008). Research has suggested that binge drinking occurs more among U.S. Army personnel who are younger and had been deployed in an area of combat (Lande et al., 2008). A study found a prevalent association 
between recent gambling, binge drinking and aggression among a sample of veterans who have reported recent substance use in a Veteran Affairs outpatient treatment (Davis et al., 2017).

Military culture creates a toughness mentality where personnel do not feel comfortable letting people know they are struggling or abusing drugs for fear of being judged or discharged. This is one reason why individuals in the military do not seek help when they are feeling depressed or struggling with substances. This often results in increased substance use, such as binge drinking (Bucher, 2011). Individuals who have served in the military report concerns of stigma as a barrier to asking for treatment (Burnett-Zeigler et al., 2011). Literature has indicated that stigma is one of the main reasons that veterans fail to seek treatment (Stecker, Fortney, Hamilton \& Ajzen, 2007).

In a 2010 survey past-month binge drinking results were slightly higher for veterans $(9.7 \%)$ than civilians (9.5\%), and reserve members (11.9\%). Consistent with the literature, findings reported "rates of binge drinking are higher among veteran men than veteran women" (Hoggatt et al., 2014, p. 27). Binge drinking and heavy alcohol use is a common occurrence for individuals in the U.S. Military (Allen et al., 2016). Military service in the United States is associated with chronic and problematic alcohol use (Fuehrlein et al., 2016). According to the research, rates from heavy drinking and binge drinking ranged from $14 \%$ to $44 \%$ in U.S. military veterans (Allen et al., 2016). 
Other branches of our military, such as the U.S. Air Force also have issues with binge drinking. According to a research study on veterans who served in the Air Force, fourteen percent of Air Force members reported serious consequences associated with binge drinking while $19 \%$ indicated productivity loss and more than $14 \%$ reported dependency problems (Taylor, Haddock, \& Poston, 2007). Serious consequences for binge drinking have also been discussed in earlier studies. According to research by Bray \& colleagues (2002), the results indicated that nearly one third of heavy binge drinkers had one or more serious consequences that were associated with alcohol use and one half reported productivity loss (Bray et al., 2002).

Another branch of our military that has reported issues with binge drinking is our United States Armed Forces. A 2013 Department of Defense survey revealed a wide occurrence of binge drinking in a U.S. Armed Forces population. The results found where $33 \%$ of personnel reported binge drinking during the 30 days prior to completing the survey. Results varied, depending on the type of military branch involvement. Results indicated that 39\% were in the Army, 38\% Navy, 49\% Marines, and 24\% Air Force (Bray et al., 2013).

Research from the Survey of Health-Related Behavior (2005), found that $43 \%$ of military personnel binge drink. The study found "more than $70 \%$ of all binge-drinking episodes involved military who were heavy drinkers means that approximately one in five ADMP reported binge drinking an average of more than twice per week" (p. 215). 
The authors indicated an estimate of 30 million episodes of binge drinking occurred every year. Translating into 30 binge drinking episodes per person (Stahre, Brewer, Fonseca, \& Naimi, 2009).

Research examined binge drinking behaviors in a sample of military personnel utilizing the 2008 HRBS data. The findings indicated that $21.5 \%$ of active duty military personnel were alcohol abstainers, $16 \%$ reported infrequent/light drinking, $17.1 \%$ reported moderate drinking, $25.5 \%$ reported moderate/heavy drinking, and $20.0 \%$ reported heavy drinking. Males had a higher proportion of heavy drinking (21.9\%) than females (8.3\%). The highest rates of heavy drinking occurred for the age group 21 to 25 years old (29.5\%), with 20 years and younger (19.0\%) and ages 26-34 (18.7\%). Finally, Individuals who were over the age of 35 had $9.6 \%$ of their sample report heavy binge drinking (Mattiko et al., 2011).

Several negative consequences associated with being in the military have caused heavy and binge drinking episodes. Consequences include being passed over for a promotion, the loss of one or more weeks from duty because of drinking-related problems, and accidents of self-harm, violence, physical and emotional consequences (Hanwella \& DeSilva, 2012; Mattiko et al., 2011). Jacobson et al. (2008), utilized the Millennium Cohort Study to evaluate the long-term health of military service members and influences of deployment. The authors found that "those deployed with combat exposures were at increased odds of new onset binge drinking at follow-up" (p. 669). 
Several reasons for drinking among 9/11 veterans included "drinking because it helps you when you feel depressed or worried" or "to forget your problems" and were all linked to binge drinking and problematic alcohol use (Whiteman \& Barry, 2011, p. 4). Cucciare et al., (2011) assessed related mental health factors such as using drugs or alcohol to cope with nightmares, stress, depression and relative social situations. The sample consisted of 554 veterans who completed an in-office home-based Behavioral Activation for Depression (BATD) treatment delivered by web-based technology. Findings indicated that binge drinking was related to "coping with nightmares/flashbacks/lack of sleep and stress/depression” (p. 365).

\section{Binge Drinking Among Women Veterans}

Binge drinking affects both men and women in the military. While men are more likely to report binge drinking episodes, women in the military still need to be noted (Ursano et al., 2016; Stahre et al., 2009). Ursano et al. (2016) examined a sample of 10,000 reserve component personnel who were enlisted as of June 2009. Participants were asked how many drinks they had consumed on the days that they drank alcohol within the past 30 days. The results indicated that binge drinking was higher for enlisted men $(14.8 \%)$ than enlisted women (2.6\%). However, the "sample was $80 \%$ males" (p. 1291). Research found that women in the military "were 1.21 times more likely to report new onset heavy weekly drinking” (Jacobson et al., 2008, p. 669). 
However, military women had higher reported binge drinking episodes than civilian women (Stahre et al., 2009). In a study of female veteran affairs patients, the authors found that $25 \%$ of their 780 respondents reported binge drinking and $39 \%$ reported having 4 or more drinks on one occasion within the past year. Results also indicated that $28 \%$ drank less than monthly, $6 \%$ drank monthly, $5 \%$ weekly, and $1 \%$ daily (Bradley et al., 2001). Similarly, in a systematic review of women veterans, the results indicated that $25 \%$ of VA patients reported binge drinking (Hoggatt et al., 2014). A similar study also indicated that men were more likely to report binge drinking than women, and white veterans were more likely to binge drink than any other race (Calhoun et al., 2008).

\section{Binge Drinking Policy and Treatment}

The Army implemented the Confidential Alcohol Treatment and Education Pilot in 2009 which demonstrated that active duty service members could use confidential treatment. The Department of Defense Military Health System also provides treatment directly and through TRICARE insurance benefits. Current Department of Defense (DoD) policy strongly discourages alcohol abuse. Defined as binge or heavy drinking, as well as illicit drug use and prescription drug misuse among members of military forces due to the negative affects these behaviors have on health, military readiness and performance (DoD, 1997). 
However, even with policies and procedures in place to combat binge drinking issues in the military, it still remains prevalent. Binge drinking in the military can result in military members being disciplined or dishonorably discharged (DoD, 1997). To some extent, the DoD exacerbated the problem by disciplining military personnel and giving them dishonorable discharge instead of helping treat the problem. More policies on treatment of not only binge drinking but all substance use and abuse problems are needed.

Group treatment is an option for soldiers who are having issues with substance abuse such as binge drinking. The group setting allows for soldiers to see that there are others who are going through similar issues. Treatment through client feedback was found to have improved outcomes for soldiers who received group treatment at an Army Substance Abuse Outpatient Treatment Program (ASAP). The results indicated that soldiers in the client feedback group had significantly more improvement and significant change as well as a higher percentage of ratings by both clinicians and commanders (Schuman et al., 2014). However, research has shown that while treatment options may work, a number of veterans do not show up for treatment program options.

One study examined medical records from veterans who were hospitalized at the Atlanta Veteran Affairs (VA) Medical Center. The authors found that homelessness was the only significant correlation with starting and completing the substance abuse treatment program (Vayalapalli et al., 2013). One interesting treatment option is 
acupuncture. Researchers examined the effects of auricular acupuncture and the relaxation response on reducing craving and anxiety, finding that craving and anxiety levels decreased significantly following the acupuncture session. The number of acupuncture sessions and relaxation was associated with a reduction in craving (Chang \& Sommers, 2014).

Individuals who have issues with binge drinking would be able to utilize alcohol abuse treatments that are available. There are several effective alcohol treatments that are in place for individuals who served in the military. For example, some available programs are cognitive behavioral therapy for relapse prevention, 12-step facilitation, community reinforcement approach, substance use disorder- focused behavioral couples counseling/family therapy, and motivational enhanced therapy (Allen et al., 2016). According to Veterans Affairs (2019), the goal of cognitive behavioral therapy is to improve symptoms of depression, develop more balanced thoughts, and help improve quality of life.

One form of treatment for alcohol is the use of Antabuse, which is a drug that is not toxic to the human body. The drug has an effect of sensitizing the patient to alcohol by interfering with the metabolism of alcohol in the body, resulting in nausea and vomiting and causing a feeling of anxiety and distress in the patient (Robinson \& Kidd, 1951). There are several military and veteran specific programs for substance use, particularly alcohol use and binge drinking, such as the Veterans Alcohol and Drug 
Dependence Rehabilitation program which is covered by Veteran Affairs. The VA has several treatment options for individuals who have substance issues, mental health issues and PTSD (U.S. Department of Veteran Affairs, 2019).

\section{Current Study}

Binge drinking behaviors can be explained using a partial test of Agnew's GST. Research has indicated that one reason individuals turn to substances is to cope with strain (Agnew, 1992). Agnew's GST can aid in explaining why binge drinking occurs in the military veterans and can help us understand how strain relates to binge drinking behaviors. The current study will also aid in the formulation of policy and procedure. As a group, military veterans provide unique opportunities for purposes of sociological and criminological inquiry. Evidence points to a disproportionate amount of strain military veterans experience due to their environment, which makes them unique in studying delinquency, specifically, binge drinking. Of appropriate theories that can be used to best explain this phenomenon, GST seems the most adequate theory to utilize as the framework of this study. The current study makes this connection in the relationship between military veterans, environment factors, strain, depression and binge drinking behaviors. The next chapter provides a broad overview of Agnew's GST and outlines the research aims and hypotheses for this study. 


\section{CHAPTER III THEORETICAL FRAMEWORK}

The current dissertation is a partial test of Agnew's $(1992,2006)$ GST with an understudied population of military veterans. This framework is suitable for this study because it argues that negative life events and/or harsh conditions influence an individual's involvement in crime and delinquency. Military veterans tend to have been involved in events and conditions conducive to strain that were described in the previous chapter. This chapter will provide an overview of GST, its central argument, how it relates to this study, and the study's research hypotheses that are grounded in theory.

Hypotheses grounded in theory are important because the hypotheses provide an opportunity to empirically test the strengths and weaknesses of the theory. While providing developments to the scholarship and overall understanding of the theory. The hypotheses grounded in theory also aid in helping the researcher carry out an outline for her study and a step-by-step plan to help reduce any vagueness in the study. Through following the GST model, the study is able to examine coping with binge drinking in a military veteran population.

\section{Theoretical Foundations of GST}


The development of Agnew's $(1992,2006)$ GST starts with the founders of classical sociology, Emile Durkheim and Robert Merton. Durkheim (1893), first coined the term anomie, or a state of normlessness to describe a condition of deregulation in society. Durkheim (1893) argues that this deregulation or normlessness is what leads to deviant behavior. He later coins the term anomie in 1897 to refer to a morally deregulated condition in which people have inadequate moral controls over their behavior. Anomie refers to the breakdown of social norms and when those norms no longer control the activity of the members of society (Cloward, 1959; Cloward \& Ohlin, 1960).

The theory states that without appropriate social controls or rules in place to regulate behavior, individuals cannot find their place in society and have difficulty adjusting. This leads to frustration, conflict and, ultimately, deviance. Durkheim found that economic crisis, forced industrialization, and commercialization as all factors which produce anomie. Later, in 1938, Merton used the concept of anomie to explain deviance in the United States (Merton, 1938). While Merton borrowed from Durkheim, he disagreed that changes and deregulation within society created anomie and believed that the key point was the ability of social systems to exercise control in the form of social norms.

Merton divided the idea of social norms into two types, societal goals and the acceptable means to achieve those goals. Merton's idea of societal norms explains how individuals who lack acceptable means to achieve those goals may result in deviance (Merton, 1938). In sum, Merton believed that deviance is a product of anomie. Merton's 
anomie theory is essentially a theory of deviance and does not necessarily study criminality. Merton's concept of deviancy is general in the fact that when society emphasizes well-structured goals for its members and an equally structured avenue to achieve those goals, deviance becomes any behavior that does not follow commonly accepted values. In other words, deviance is anything that is not considered normal in society.

Merton's research focused more on individual explanations of deviance rather than society. Agnew $(1992,2006)$ extended Merton's work and furthered the anomie perspective by claiming that other types of strain exist and have effects on anyone who experiences them. Agnew's most significant contribution to the strain theory was his perspective on the importance of emotions. Negative emotions such as frustration, anger, and depression affect relationships between people and situations.

\section{Central Tenets of GST}

Agnew's (1992) GST focuses on three general types of strain. The first type of strain explaining why individuals engage in crime is the actual or anticipated failure to achieve positively valued goals such as money, status or respect. The second type of strain is the actual or threatened removal of positively valued stimuli; this could be in terms of job loss, homelessness or a breakup in a relationship. The third and final tenet of GST is the actual or threatened presentation of negative stimuli such as criminal victimization, child abuse, or negative school and work experiences (Agnew \& White, 
1992; Agnew, Brezina, Wright \& Cullen, 2002; Sigfusdottir, Kristjannson, \& Agnew, 2012).

Agnew (1992) felt that classical strain theory focused on the inability to attain future economic success and did not do a decent job explaining current stressors, specifically for juveniles. To address this, he applied strain theory as an extension of Merton's anomie theory, with the addition of explaining it at the individual level (Agnew, 1987). Merton focused on non-organized society based on his conception of the cultural and social structure, examining cultural goals and institutional means. Merton only focused on a limited type of goal, which was monetary or material accumulation. Agnew continued the focus of Strain Theory research on a more individual level, first by broadening the scope of strain and then including strains from aversive situations and individual level goals such as good school grades.

Merton's modes of adaption focused on ways that individuals cope with strain. Merton's five modes of adaptions are conformity, innovation, ritualism, retreatism and rebellion. Each of these adaptions addresses how an individual will cope with the pressure of strain. Conformity explains how an individual strives for the American dream by conforming or obeying the rules of society. Innovation describes individuals who accept the American dream but take a more illegal route to achieving those means by no longer employing the socially approved means for doing so. 
The third mode of adaption, ritualism believes that there is no American dream, but individuals still accept the rules of society merely out of habit. Retreatism describes an individual who abandons both the American dream and the effort or ambition that citizens are expected to have. Retreatists reject both the American dream and the rules individuals are supposed to follow. Finally, rebellion is the individual who rejects the American dream and replaces it with a different set of goals and means (Merton, 1938). Agnew's GST broadens the range and causes of strain and is able to depart from Merton's adaptions. In doing so, Agnew was able to develop a more general means of coping with strain. He expands the argument of strain at the individual level by also including economic strains and explained the differences across socioeconomic status levels as well as including social psychological dimensions such as negative emotions (Agnew, 1992). Agnew was able to expand the sources of strain from one cause to three, which is where the central tenants of GST are introduced. The three central tenants include the failure to achieve positively valued goals, the removal of positively valued stimuli, and the introduction of negative stimuli.

Agnew (1992) believed that individuals who experience strain will attempt to correct their strain by choosing a beneficial coping mechanism. However, this will only occur after becoming emotional (anger, frustration, depression). According to the GST literature, Agnew discussed many definitions of emotions, but the central component of an emotion is an evaluation of or an effective response to some idea or behavior. One 
person may have the negative emotion of anger, while another may have a negative emotion of stress or anxiety.

Agnew argues that strain theory has a vital role in explaining crime and delinquency (Agnew, 1992). GST distinguishes itself from social control and social learning theory through its specification of the type of social relationship that leads to delinquency and the motivation for delinquency. Strain theory begins by focusing specifically on the negative relationship with others. Negative relationships will likely lead to anger and frustration which may also lead to delinquent behavior.

Agnew broadened the focus of GST to include relationships where others present the negative stimuli (Agnew, 1987). Strain theory further argues that adolescents are pressured into delinquency by negative affect states, such as anger and related emotions, that result from negative relationships with others. Agnew (1992) believed that negative relationships with others is "relationships in which others are not treating the individual as he or she would like to be treated" (p. 50). Negative relationships are ones that prevent the individual from achieving positively valued goals. According to Agnew (1992), "This negative affect creates pressure for corrective action and may lead adolescents to make use of illegitimate channels of goal achievement, attack or escape from the source of their adversity, and manage their negative affect through the use of illicit drugs" (Agnew, 1992, p. 49). 
According to Agnew (1992), the emotions that are most closely connected with the three types of strains are disappointment, depression, fear, and anger. Anger being the most critical emotional reaction for the purposes of the theory (p. 52). Individuals become angry when someone blames his or her own adversity on others and its deceitful emotion (p. 59). Anger is viewed as increasing the individual's level of perceived injury, which creates a desire for revenge. This, in turn, lowers inhibition and motivates some sort of corrective action (p. 49).

Agnew explains that the experienced strain will then create a negative emotional affect (e.g., anger, frustration, disappointment, fear, depression, anxiety) within individuals. Crime is seen as a result of negative emotional affect such as depression, and a way for individuals to reduce or escape from strain. Agnew $(2001,2006)$ states that a range of strains or negative events increase crime. The strains that lead to negative emotions will create pressure for corrective action. Agnew posits that one way to cope with these strains and negative emotion is through crime and deviancy.

Agnew (1992) argues that some of these coping strategies can be cognitive, behavioral and emotional. Agnew believes that delinquency is determined by a number of factors such as the constraints of non-delinquent and delinquent coping and the disposition to engage in delinquent verses delinquent coping (Agnew, 1992). Negative affect creates pressure for corrective action and can lead to illegitimate channels of goal achievement and coping with delinquent behavior such as drug use (p. 49). In sum, 
Agnew believes that delinquency or crime is a way to alleviate negative emotion, feelings of strain, feelings of anger, frustration, depression (Agnew, 1992).

Agnew (2006) distinguishes strain as either objective or subjective. Objective strains are strains or events that most people as a collective group dislike. Subjective strains are events or conditions that are disliked by the people who experience them and are more likely to lead to crime. In other words, they are strains to which everyone reacts differently. For example, Wheaton (1990) examined a subjective evaluation of divorce and found that some people view divorce in a positive light, while others may view it as negative (p. 216). Agnew found that both objective and subjective evaluations may impact crime, but that subjective strains may have a greater effect (Agnew, 2006).

Agnew (2001) discusses how crime and delinquency might be the outcome when strains are seen as high in magnitude (severe), frequent, long in duration, recent and expected to continue into the future. Strains that are favorable to crime are also seen as unjust, such as a deliberate strain against someone. Third, strains that are caused by or associated with low social control, such as parental discipline, low attachment from parental rejection, and low commitment or homelessness are favorable to crime (p. 335). The final characteristic is when strains create some form of pressure or incentive for corrective action, of criminal coping. An example of corrective action would be viewing crime as a way to right a wrong, such as theft, seeking revenge, or alleviating negative emotion with illicit drug use (p. 319). 
According to Agnew $(2001,2006)$ anger is conducive to crime because it energizes individuals for action, creates a desire for revenge, and provides a justification for crime. It is important to note that not all individuals who experience strain and anger commit crimes. There are several factors that influence whether individuals engage in some form of criminal coping. These factors include coping skills, self-efficacy, selfesteem and financial resources. Financial, emotional, and other social supports are important factors in reducing the change of an individual engaging in criminal coping actions.

Agnew (2012) acknowledged that individuals only turn to criminal coping after they have attempted to cope with strain through legitimate means. Criminal coping occurs when the benefits of crime are high, and the costs are low. When an individual has very little to lose by engaging in crime, such as weak family ties, little interest in school or when someone does not have a job, the chance of criminal coping is higher. Having criminal peers also increases the likelihood of criminal coping by reinforcing criminal behavior and justifying criminal acts as appropriate responses to strain. All of these different pathways to crime illustrate the complexity of coping due to its influence by several factors across multiple stages. Certain factors are more conducive for individuals to engage in criminal coping, such as poor coping skills and a lack of social support.

\section{Negative Emotional States}


As mentioned above, one of the central tenets of GST is the idea that certain strains produce a range of negative emotions and a way to alleviate those emotions is through crime and delinquency. Agnew (2006) makes a distinction between emotional states and emotional traits. Emotional states have more to do with the actual experience of an emotion, whereas emotional traits deal with the general tendency to experience certain emotions. For example, an individual who experiences the state of depression or is suffering from a mental illness may be depressed without an immediate cause, while another person may be depressed because he/she experienced a stressful event. Agnew included emotions within GST, with the view that negative emotions are what paves the way and creates pressure for a corrective action (Agnew, 2006).

Agnew proposed a number of conditioning factors that would make some people more susceptible to participating in criminal behavior (1992). Later, Agnew recognized that the most important contributing factor to crime among strained persons was personality factors. Negative emotionality was identified as the biggest reason that strain led to criminal and deviant behavior. Negative emotionality, according to Agnew, refers to a personality type that readily and habitually draws conclusions about events. Agnew et al., (2002), found that individuals with high negative emotionality tend to experience events as aversive, experience intense emotional reactions and respond in an aggressive or antisocial manner. 
While emotional traits have a role in the GST framework, the current study focuses on the relationship between strain, emotional states, and crime, specifically binge drinking. The idea of negative emotions resulting from strain, such as depression, increasing the likelihood of crime and deviancy seems pretty straightforward. The idea that upon experiencing strain, people want to participate in some sort of corrective action to lessen the feeling of stress makes sense and can be applied to several aspects of life. Negative emotional states also tend to lower the ability to find legitimate coping mechanisms, resulting in cognitive, behavioral or emotional coping skills that often create a disposition for crime (Agnew, 2006). The goal of this study will utilize the GST framework to aid in explaining depressive emotions, characteristics of strain and how it affects binge drinking behaviors in military veterans.

The current study focuses on the emotional state of depression. Depression can be generally defined as "a common and serious medical illness that negatively affects how you feel, the way you think and how you act" (APA, 2013 p. 1). Depression "causes feelings of sadness and/or a loss of interest in activities once enjoyed and can lead to a variety of emotional and physical problems and can decrease a person's ability to function at work and at home" (APA, 2013 p. 1). Depressed people also feel like they have nothing to lose by engaging in criminal activity (Agnew, 2006). Agnew (2006) argues that the emotional state of depression increases the likelihood of illegitimate forms of coping such as binge drinking because individuals may feel powerless. 


\section{Experiences of Strain by Military Veterans}

Research has shown that, in general, individuals who have been in the military experience different types of stressors, have more negative life events and employ different coping mechanisms than those in the civilian population (Bray et al., 1999; Pflanz \& Ogle, 2006). Stress is high for military veterans for a multitude of reasons, which include having been away from their family and friends, financial issues, homelessness and possible health related issues such as anxiety and/or depression. GST utilizing a military veteran population provides us with a roadmap of variables to examine. As mentioned in the section above, goal blockage, negative stimuli, the removal of positive stimuli and coping are all indicators that cause strain. This section provided the basis of GST and how it applies to military veterans.

There are several characteristics from the military lifestyle that causes stress in military veterans. A few stressors include deployment, exposure to trauma, frequent assignments, competitive career environment, discipline and hierarchical structure. However, this dissertation will focus on only a handful of stressors, namely financial issues, employment, combat, health issues, age, gender, and marital status in military veterans.

\section{Financial Stress/ Employment}

Veterans consist of a disproportionate amount of the United States homeless population. According to Perl, (2011), one of every four homeless individuals in the 
United States served in the military at some point. Research found that veteran women are four times more likely to be homeless than non-veteran women (Gamache, Rosenheck \& Tessler, 2003). For example, 72\% of veterans experienced high levels of stress upon transitioning back to civilian life through difficulties finding employment, interpersonal issues, family conflicts and difficulties adapting to civilian life (Morin, 2011).

Termination from the military may also cause stress, as well as, conflicts with supervisors and peers, operational tempo, housing problems, financial problems, medical fitness for duty, martial conflicts, deployment-related communication problems and childcare (Lande, 2014).Unemployment was one of the primary risk factors for homelessness among women veterans (Washington et al., 2010). High associations are found between combat veterans and unemployment rates (MacLean, 2010). Findings suggest that "combat indirectly increased unemployment, in part, by increasing disability" (p. 576).

\section{Deployment: Combat}

GST posits that negative stimuli are a significant source of strain. In terms of negative stimuli present in the military, deployment and combat are significant stressors that are present. Stressors from negative stimuli can cause negative coping mechanisms, such as binge drinking. Binge drinking during deployment can have several negative effects on military readiness and safety. However, the stress of deployment often 
increases the use of binge drinking for individuals who served in the military. Binge drinking often follows veterans after they retire. There are a number of reasons why deployment is related to binge drinking for those who served in the military, including changes in social support, perceptions and experiences of stress, access, supervision and the normative attitude of substances.

Stress often increases the likelihood of substance use such as binge drinking (Federman et al., 2000). The findings resulted in an increase in heavy drinking among deployed women; however, heavy drinking among women is lower than male drinking. Heavy drinking is three times higher among deployed women than non-deployed women (p. 218). Rothberg et al., (1994) examined drug and alcohol healthcare service utilization rates among U.S. Army deployed in the Persian Gulf War and found that substance and alcohol use was higher for those who were deployed.

Combat exposure during deployment is also a significant predictor of binge drinking issues. Soldiers who experience combat are also at risk for poor health and quality of life (Sheffler, Ryshing, Stanley \& Ericsson, 2016). Research has shown that the quality of life for soldiers who have been deployed is lower than those who have not been deployed (Polusny et al., 2011). A study from Operation: SAFETY (Soldiers and Families Excelling Through the Years) found that male soldiers who were deployed had a lower quality of life factor that may influence substance use with evidence suggesting that combat is associated with increased risk in alcohol and illicit substance use problems 
(Hoopsick et al., 2018). In a study of health effects of deployment, specifically deployment in a combat zone in Iraq and Afghanistan found that anxiety was the most commonly observed long-term mental health outcome, followed by depression and problem drinking (Ciarleglio et al., 2018).

\section{Depression}

Depression has been examined among U.S. military veterans with results indicating that military veterans have significantly greater levels of sleep disturbance, depression, and PTSD symptomatology than non-veteran civilian counterparts (Bartlett, 2018). Military veterans also had higher rates of clinical depression than non-veteran counterparts (p. 397). Military veterans often have depression combined with posttraumatic stress disorder or traumatic brain injury (Byers \& Yaffe, 2014). Deployment to Iraq and Afghanistan was also associated with higher odds of major depression (Shen, Arkes, \& Williams, 2012).

Goldstein et al., 2017 examined depression in military veterans and found that certain types of traumatic military experiences were associated with PTSD and depression (p. 284). A study of depression in military veterans used in-office to homebased Behavioral Activation for Depression (BATD) treatment delivered via web-based video technology. The authors found that home-based treatments are more effective when dealing with military veterans (Luxton et al., 2014). In addition, home-based 
treatments were more suited for patients who were already at home and more feasible for military veteran schedules (p. 143).

\section{Coping with Strain}

Military veterans use multiple coping factors to handle experiences of strain. The use of avoidance coping is used to explain associations between PTSD and substance use (Boden et al., 2014; Baker et al., 2004; Litman, 2006). For veterans who have PTSD, alcohol and drugs are used as an avoidant strategy to alleviate stress (Baker et al., 2004). However, there are several active coping strategies oriented toward unpleasant experiences such as positive reappraisal and problem solving (Litman, 2006).

Research indicated that emotional discharge coping is positively associated with PTSD symptoms (Boden et al., 2014). Active coping was not associated with either PTSD or SUD symptoms. However, active coping increased, and avoidance and emotional discharge coping decreased during a 12-month time frame after participants received therapy (p. 164). Of the 98 male veterans studied, SUD treatments increased adaptive coping such as including strategies of active coping, problem solving, positive reappraisal and decreased maladaptive coping (p. 165).

\section{Emotional Coping: Binge Drinking}

Veterans often have experienced stress from their experience of serving in the military as well as difficulties adjusting to civilian life. Ways that veterans often cope with stress is through emotional coping, such as binge drinking. Emotional coping is a 
stress management strategy where the focus is on regulating emotional reactions to stress (APA, 2019). Binge drinking in veterans is often associated with mental health factors such as symptoms of PTSD and depression (Bradley et al., 2001). Stress or depression was associated with increased occurrence of binge drinking (Cucciare et al., 2011).

Research has indicated that binge drinking is relatively common among military veterans. Veterans often engage in binge drinking to cope with negative emotions and mental health problems (Bradley et al., 2001). Veterans were also more likely to engage in binge drinking and physical aggression (Davis et al., 2017). Strong associations were also found between military rank and binge drinking (Cucciare et al., 2015). Research findings also indicated that binge drinking was higher among women (p. 39). Deployment status and combat exposure was also highly associated with binge drinking (p. 40). Jacobson et al., (2008) found a high likelihood of post-deployment binge drinking among a male sample of service members.

\section{Gender and Age}

Research has indicated that men have a stronger integration between negative emotion and craving. According to the literature, elevated rates of heavy drinking are found among women veterans compared to non-veterans (Ames \& Cunradi, 2004). Studies have shown that women are more likely to have the negative emotion response of anger, and it is more likely followed by depression or guilt (Campbell et al., 1992). Gender is another important component for analyzing GST. Studying gender, specifically 
in terms of military women, may be an effective way to understand women's rates of binge drinking compared to their male counterparts.

According to the U.S. Census, there are nearly 1.6 million women veterans in the United States, and approximately $11.4 \%$ use Veteran Affairs for healthcare. Women have different stressors than their male counterparts may have. Their health care may have different needs than males require (Goldzweig et al., 2006). Women are more likely to develop mood disorders, such as depression (Erickson et al., 2001). A study found that $25 \%$ of a sample of 1,243 women veterans at a VA hospital reported issues with binge drinking. The same study reported homelessness being prevalent in $1.6 \%$ of female veterans and are likely to be diagnosed with a major psychiatric disorder (Bradley et al., 2001).

Women in the military have unique experiences that may affect binge drinking differently than military men. Women were also more likely than men to be diagnosed with affective disorders. Of the 225 female veterans at a Veterans Health Administration (VHA) women's health clinic, 37\% had symptoms of depression (Bader et al., 2001). Currently, women consist of $15 \%$ of the active duty force (Aponte et al., 2017).

In another study on stress issues and gender in the military, researchers examined data from the 2013 Canadian Forces Mental Health Survey and found that trauma experienced while on deployment does not disproportionately affect women in the military (Frank, Zamorski, Lee \& Colman, 2018). Other studies also corroborate that 
there is no gender-difference in deployment effects (Jacobson, Donoho, Crum-Cianflone, \& Maguen, 2015; Maguen, Luxton, Skopp \& Madden, 2012). However, research did find that women were three times more likely to report PTSD than men (Frank, Zamborski, Lee \& Colman, 2018). It is important to examine gender differences related to stress in military experiences as they effect men and women differently.

Literature on women's exposure to combat has been limited due to small samples. In a study of U.S. female and male veterans, the authors found that female members from OEF/OIF may be as resilient to combat-related stress as men (Vogt, et al., 2011). Another study found that women were significantly more likely than men to screen positive for general mental health problems when exposed to combat (MHAT-IV, 2006). Research examined a random stratified sample of 2,000 OEF/OIF military personnel from the Defense Manpower Data Center (DMDC) and found that women reported significantly more exposure to prior life stressors and deployment sexual harassment (Vogt et al., 2011).

Studies have shown that military base dormitories house substance users and nonusers. This results in an increased risk of drug use at a young age by draftees who started off training as a non-user (Green, Hunter, Bray, Pemberton \& Williams, 2008). For veterans, being a younger age increased the odds of binge drinking episodes (Cucciare et al., 2011). Binge drinking occurred among younger veterans, specifically 
between the ages of 18-25 (Bray et al., 2002). Binge drinking was higher among female veterans aged 35 or younger (Bradley et al., 2001).

\section{Military, Strain, and Crime}

The development of binge drinking in military veterans occurs for a variety of reasons. One explanation that can shed light on the topic is the issue of stress and strain that accompanies military environments. Substance use and abuse such as binge drinking often occurs as a result of illegitimate coping strategies from stressors and strains of veterans' environment (Baker, Piper, McCarthy, Majeskie, Fiore, 2004; Sinha, 2008). Agnew's GST can shed some light on how and why binge drinking occurs as a coping mechanism for military veterans and a way to help recognize and treat the issue. Using Agnew's GST, we can also posit a suggestion for a better form of treatment for individuals experiencing strain to prevent further binge drinking episodes.

Distinctions are made within the GST literature to explain nuances between specific groups such as military veterans. Bucher (2011) applies GST to explain delinquency in a military population. The author examined a sample of 50 army personnel using purposive snowball sampling. Findings indicated that strain was reported in combat exposure, anomie, and coping occurred through substance use, violence and theft. According to the GST literature, goal blockage, the introduction of negative stimuli and the removal of positive stimuli can lead to anger, frustration and depression that are associated with strain in criminology (Agnew, 1992). The current dissertation will focus 
on two of Agnew's central tenants, removal of positive stimuli and the introduction of negative stimuli.

\section{Removal of Positive Stimuli: Employment}

A central component of GST is the removal of positive stimuli. Agnew (2006) argues that loss of positive stimuli will lead to involvement in crime. This type of strain fits well within the GST model. There have been numerous studies in the recent years suggesting a link between loss of positive stimuli and deviancy. In terms of military veterans, having unstable employment or unemployment could be viewed as a loss of positive stimuli. One aspect of strain that is present in military veterans is found in the area of family.

Strain can be placed on the families due to them being single family households once the soldier is deployed. Strain can also be placed on veterans and families of veterans who have difficulty keeping a home. According to the U.S. Department of Veterans Affairs (2013), recent estimates indicate that veterans are overrepresented in the United States' homeless population. Veterans consist of $12.3 \%$ of all of the homeless population in the United States, with only $9.7 \%$ of the total U.S. population.

\section{Introduction of Negative Stimuli: Combat \& Health}

Just as removal of positive stimuli can be a source of strain, negative stimuli, such as being involved in combat, can be a significant source of strain as well. There are several examples of negative stimuli in the military; one significant example is combat 
(Bucher, 2011). According to Bucher (2011), other negative stimuli could include "demotions, sanctions/punishments, physical pain from training, and verbal interaction with superiors (i.e., yelling)" can all follow a service member when they become a veteran (p. 850). These types of aspects within the military environment and after an individual becomes a veteran could be considered negative stimuli which would contribute to stress, anger, frustration and strain (Bucher, 2011).

Military veterans experience unique health issues during and after deployment. Research has indicated that veterans aged 18-44 are the most at risk for suicide (Olenick, Flowers \& Diaz, 2015). Approximately 49,933 veterans are homeless and face health difficulties (p. 635). An estimate of $82 \%$ OEF and OIF veterans reported issues with chronic pain and 1,573 veterans who served suffered major loss of limbs and amputations from battle injuries since 2010 (Fischer, 2015). Veterans also have had past exposures to chemicals, radiation, air pollutants, occupational hazards, noise, and vibration which increased risk for health problems. There are long term consequences for Vietnam veterans who had been implicated in Agent Orange exposure (U.S. Department of Veteran Affairs, 2019).

\section{Coping: Binge Drinking}

Agnew (1992) explains how crime involves the level of strain an individual experience and the extent and type of coping mechanisms that are available to the individual. The theory posits that people who find legitimate coping mechanisms will not 
engage in criminal behavior. However, those who do not have legitimate coping mechanisms may turn to crime or deviance to alleviate that strain. According to Ahmadi and Green (2001), stress of military life combined with early marriages and children, places military service members at risk for the development of adverse coping mechanisms. Research found that alcohol is used as a coping mechanism for stressful or traumatic events as well as self-medication for mental health problems (Thomas et al., 2010).

There are several types of coping strategies utilized when adapting to strain. According to Agnew (1992), there are cognitive, emotional, and behavioral adaptions to strain. Cognitive coping strategies are used to minimize their subjective adversity. This might include, for example, using phrases such as "It's not important," "It's not that bad" and "I deserve it" (p. 66). The individual experiencing the strain will try and ignore or minimize the importance of adversity by reducing the relative importance they assigned to the goal and or/value they did not achieve (p. 67). Agnew (1992) also explains how individuals will maximize positive outcomes and minimize negative outcomes by lowering the standards that they use for expected outcomes. Also, the individual could minimize the subjective adversity of objective strain by accepting responsibility and convincing themselves that they deserved it (p. 68).

Emotional coping strategies occur by acting directly on the negative emotions that resulted from adversity (Agnew, 1992). Emotional coping can result in the use of drugs, 
physical exercise, deep-breathing techniques, meditation and behavioral manipulation (Rosenberg, 1990). The purpose behind these actions is to alleviate the negative emotion rather than cognitively reinterpreting or altering the situation where the negative emotions came from (Agnew, 1992). An emotional coping strategy that is often used in military veterans is binge drinking. According to Osilla et al., (2017), one quarter of military veterans between the ages of 18 and 35 binge drank in the past month as a coping mechanism.

In regard to military veterans, there is a perceived stigma associated with treatment, resulting in fewer legitimate opportunities for coping (Miller et al., 2017). Veterans believe they will be viewed as weak if they ask for care, help or seek treatment (p. 3). This is where the toughness mentality comes into effect, where the individuals in the military are supposed to be tough and not demonstrate any signs of weakness. This type of toughness mentality is embedded into soldiers, which in turn creates an environment where soldiers feel unable to express their strains or stressors (Bucher, 2011).

Bucher (2011) found that soldiers feel they should not talk about what is bothering them or acknowledge that anything is bothering them at all (p. 866). The findings indicated that the pressure to not show emotion is keeping soldiers from asking for help or finding sources of support. While there is an outlet available for coping, people who have been in the military believe there is an understanding among one 
another that these outlets are not to be used (Bucher, 2011, p. 867). This kind of mentality can follow them even after they are released from the military and are deemed veterans.

Research among cadets in a Greek military medicine undergraduate program found that $25.20 \%$ of servicemen $(n=279)$ had depressive symptoms. The study indicated an association between depressive symptoms in soldiers that had a higher education and served in the military for a shorter time (Xiong, Zhang, Zhang, Ma, \& Li 2005). Bareis and Mezuk (2016) also found that military service was marginally associated with major depression. Early life experiences, such as education, marital status, childhood mental illness and childhood poverty that are independent of military service, appear to be associated with a greater odd for depression.

Research found that veterans who served in the all-volunteer era had a higher likelihood of depression. Of veterans from the all-volunteer era, 24\% had major depression compared to $12 \%$ of civilians (Bareis and Mezul, 2016, p. 1). Stress, issues with coping and military environment are interrelated. Research indicated that anxiety and depression predicted reasons for binge drinking (McDevitt-Murphy et al., 2010).

\section{Cultural Nuances of Responses to Strain by Military}

The underlying argument of this dissertation is that veterans tend to experience certain types of strain that may lead to binge drinking. Veterans who respond to strain with binge drinking may further be influenced by emotional states (i.e., depression). 
However, alcohol is a central nervous system depressant and may cause increased depression (CDC, 2019). For example, the coping skills and social support systems that are in place for military veterans are shaped by cultural nuances related to the military environment. Military veterans tend to have poor coping skills, such as not talking about their issues, not seeking help and binge drinking as a coping mechanism (Bucher, 2011). The author also explains that this type of poor coping skills is due to the military toughness mentality and the stigma associated with asking for treatment (p. 866).

Social support networks, however, can have negative implications as well when it comes to individuals who have been in the military. Military veterans may choose not to seek help from social support networks due to the cultural beliefs in toughness or being able to handle their own problems (Brown et al., 2011; Valenstein et al., 2014). Miedzian (1991) stated that military creates an environment that is hyper masculine and has an emphasis on extreme behavior, toughness and the lack of emotion. This kind of toughness mentality is so embedded into soldiers that it creates an environment where they feel unable to express issues with strains or stressors such as PTSD or binge drinking (Bucher, 2011).

While there are policies and procedures in place for social support networks to help soldiers, research has shown that there still is a stigma attached to utilizing them and admitting weakness (Pruitt, Luxton \& Shore, 2014). Programs that are available are the Confidential Alcohol Treatment and Education Pilot as well as multiple DoD policies on 
alcohol and drug abuse. Several military personnel and veterans avoid treatment all together due to the stigma associated with going (Hammarlund, Crapanzano, Luce, Mulligan \& Ward, 2018). This could explain why a large proportion of military veterans do not utilize social support networks.

\section{Research Hypotheses}

The overall goal of the current study is to investigate types of strain that are most conducive to deviant behavior. Specifically, the current study will focus on binge drinking among a sample of military veterans. The current study intends to focus on issues of depression as well as other strain variables. In examining the model, there are several specific hypotheses of the study that should be discussed.

The hypotheses for the current dissertation include:

H1: Veterans who experience strain (unemployment) will be more likely to engage in binge drinking than those who did not experience unemployment.

$\mathrm{H} 2$ : Veterans who experienced strain (combat) will be more likely to engage in binge drinking than veterans who did not experience combat.

H3: Binge drinking will increase with veterans who experience negative emotions (depression).

H4: The likelihood of engaging in binge drinking will increase in veterans who experience health issues. 
H5: I expect biological sex, age and marital status differences in binge drinking among veterans.

Previous literature has used GST to explain relationships between sources of strain within the military population and transitions into civilian life. These studies have helped strengthen GST arguments on how stress and strain in veterans can lead to delinquency. However, taking into consideration strain in military veterans leading to binge drinking issues has very rarely been researched. Thus, this dissertation provides the opportunity to add to the literature of GST, military veteran stress, depression and binge drinking issues in significant ways. The next chapter will present the methodology used to empirically test the listed hypotheses. 


\section{CHAPTER IV METHODOLOGY}

The previous two chapters provided the theoretical framework for this study and reviewed the existing literature in relation to strain and crime among individuals in the military. The hypotheses were described at the end of Chapter 3. This chapter intends to explain the methodology undertaken to examine the research hypotheses, beginning with a description of the sample for this study. Additionally, the dependent and independent variables used in the current study will be described in detail. The data analysis related to the study will be provided under the analytical strategy.

National Survey of Drug Use and Health (2015-2017)

\section{Description of the study population}

Data for this study were collected as part of a larger study on how drug use was related to health issues among the general population. This study utilizes secondary analysis of existing data from the NSDUH, 2015-2017. The NSDUH is a nationwide study sponsored by Substance Abuse and Mental Health Administration (SAMSHA). This is an annual survey conducted by the Research Triangle Institute (RTI International) that provides information on the United States' use of tobacco, alcohol, and other types ofsubstances as well as mental health and health-related issues. The Public Health 
Service Act, Section 505, authorized the NSDUH data collection and states information about substance abuse and mental illness prevalence be collected every year (NSDUH). This survey is cross-sectional in nature, meaning each individual is not followed up on every year.

Data collection of the NSDUH is a household interview survey that is conducted in two phases: the screening phase and the interview phase. During the screening phase, the interviewer conducts a screening of the sampled household with an adult resident who is over the age of 18 in order to determine whether zero, one or two residents age 12 or older should be selected for the interview. Data collection during the interview portion consists of a computer-assisted self-interview (CAI) by a field researcher and an audio computer-assisted self-interview (ACASI) in which the respondents read or listen to the question and enter their answers directly into the laptop computer provided by NSDUH. The ACASI is designed for accurate reporting by providing respondents with a private and confidential way for responding to personal questions such as drug use, mental health and other sensitive behaviors.

Questions included in the survey cover age at first time of use, lifetime, annual and past month substance usage such as marijuana, cocaine, heroin, hallucinogens, inhalants, tobacco, alcohol and a variety of prescription medications. Questions include treatment history and demographic information (e.g., age, race, gender, and ethnicity). The survey includes questions from the Diagnostic and Statistical Manual (DSM-5) of Mental Disorders, which allows for diagnostic criteria to be applied. Respondents were 
asked questions about personal and family income sources, health care and access coverage.

\section{NSDUH eligibility criteria}

The study population consists of United States civilians who are noninstitutionalized and at least 12 years of age. Active-duty military personnel and individuals who live in an institutionalized environment such as hospitals, prisons, nursing homes and treatment centers are not surveyed. After residential homes are randomly selected, the field interviewers are sent to the selected homes. The potential participants are then selected and screened. Screening questions include information on their age, gender, race, residency status and language. Individuals who did not speak English or Spanish were not interviewed.

\section{Sampling Procedure}

Since 1999, the NSDUH employed a multistage area probability sample that is representative of both the nation as a whole and for each of the 50 states and the District of Columbia. The collection mode of the survey changed from personal interviews and self-fill answer sheets to a computer-assisted format. Each year over 65,000 participants are interviewed for the survey. The process of the multistage sampling includes dividing each state into smaller geographic areas so that dwelling units can be screened and recruited.

\section{Format of self-administered substance use sections}


The NSDUH substance use section included legal substances with age restrictions (i.e., alcohol and tobacco), illicit substances (i.e., pain relievers, tranquilizers, sedatives and stimulants). In 2015 the survey added another substance use section to include methamphetamines. Questions asked the participants about how frequently they used substances during the past month, past year and lifetime usage.

\section{The Current Study: Binge drinking issues in veterans \\ Inclusion criteria}

The focus of the current study is on binge drinking issues within a military veteran population. Utilizing data from the NSDUH compilation years of 2015-2017, the data on military veterans were obtained through the measure of now separated/retired from active duty. The 2015-2017 survey participants who declared they served in the military, but were retired when the survey was administered, were selected for this analysis. The current dissertation will be focusing on two samples. The first sample is of veterans only $(n=962)$. The second sample is of veterans that have combat experience $(n=453)$.

\section{Measures}

All variables that are assessed in the current study are utilized from the publicly available datasets from 2015 to 2017 . The data are self-report measures from the participants in the study. The following subsections will describe the variables that are used during the current analysis which are based on the GST conceptual framework. Data 
were collected across several domains during the screening process and interviews using ACASI. Several types of variables were included in the analytic approach to examine the statistical relationships among them: independent, dependent, and control variables.

\section{Dependent Variable: Binge Drinking}

The dependent variable examined in this study is involvement in binge drinking. In 2015, the NSDUH measure for binge drinking alcohol was updated to at least 4 or 5 logically assigned for female respondents. This is to reflect the change in the threshold for binge drinking use among female respondents from 5 or more drinks on an occasion prior to 2015 to 4 or more drinks on an occasion in 2015 (CDC, 2019).

The threshold for male respondents remained the same, and the men were asked to report 5 or more drinks on the same occasion in the past 30 days. The variable for binge drinking is a numerical variable which asks, number of days had four/five or more drinks in the past 30 days and is answered with a range of $0-30$. With the responses resulting in 0 equals 0 days 1 equals 1 day, etc. This variable will be recoded into a dichotomous variable that reflects the following: "Have you had four/five or more drinks in the past 30 days." The data were recoded so that (0) no and (1) yes. In this form, males and females are held to the same 5 or more standard for binge drinking without any way to distinguish between the biological sexes.

\section{Independent Variables: Measures of Strain}


The current dissertation examines GST through a handful of measures. The independent variables consist of the measures of strain in relation to the current study. These specific measures of strain account for Agnew's (1992) Strain Theory components of failure to achieve positive stimuli, removal of positive stimuli and negative affect, as well as coping strategy. The measured strain was designed to gauge the experiences of military veterans based on their abilities or inabilities to overcome situations of strain. The independent variables were used to examine their associations with binge drinking in our sample of veterans.

Removal of Positive Stimuli (Unemployed). The second concept of Agnew's (1992) GST is the removal of positive stimuli. Two measures were found in the data to adequately addressed this concept. The first measure was unemployed. The unemployed will be recoded as a dichotomous variable, measured as (1) unemployed, (0) employed.

Introduction of Negative Stimuli. The third major concept of Agnew's (1992) GST is the introduction of negative stimuli. In this dissertation, there are two measures of negative stimuli and they include the following: combat experience and health.

Combat. The first measure assesses combat experience with Ever been in a combat zone on active duty measured as a dichotomous variable $(0=\mathrm{no})$, and $(1=\mathrm{yes})$. Note that while there are 26,000 missing cases, this measure serves as a measurement of introduction of negative stimulus and is integral in measuring strain in military veterans. 
Health (Poor Health). The second measure addresses the overall health of our sample of military veterans. The overall health measure is captured at the ordinal level with responses as $(1=$ excellent $),(2=$ very good $),(3=$ good $),(4=$ Fair/poor $)$.

Negative Emotional Affect (Depression). Agnew (1992) explained that the experienced strain will then create a negative emotional affect (e.g., anger, frustration, disappointment, fear, depression, anxiety) within individuals. The measure used in the current study to address negative affect is depression measured with lifetime of major depressive disorder. In this measure, respondents were classified as having a major depressive episode in their lifetime if they reported experiencing at least 5 out of the 9 criteria used to define adult major depressive episodes. The variable adult: lifetime major depressive episode $(M D E)$ is a dichotomous variable with responses of (0) no and (1) yes.

\section{Control Measures}

Certain demographics, legal history factors, and recruitment status were included in the analysis as control variables. This data was collected in the NSDUH annually. The demographics included were age, race and gender, income, marital status and education. The age measure had a numeric age category and a final edited age category, which was "noted after a respondent has entered his/her birthday in the first part of the questionnaire, he/she has multiple opportunities to change his/her age in response to consistency checks throughout the questionnaire" (NSDUH, 2002-2017, p. 1029). 
Age. The current analysis used the age category, variable. Those over the age of 18 were included in the analysis. Age is captured using three categories and they are as follows: (1) 18-25, (2) 25-26, (3) 35 and older.

Biological Sex (Female). A control measure for the current dissertation is the measure of gender. The female variable and was measured as (0) male and (1) female. Beginning in the 2002 survey, missing values for the gender variable were no longer permitted. The purpose of this measure is to see if there are significant inter-group differences in binge drinking, when male and female veterans are compared.

Race/Ethnicity (White). Race/ethnicity was recoded as (1) white (0) non-white.

Total Household Income (Income). Income is another control measure that is used for the current dissertation. The variable used was total family income and measured as (1) less than $\$ 20,000,(2) \$ 20,000-\$ 49,000$, (3) $\$ 50,000-\$ 74,999$, and (4) $\$ 75,000$ or more.

Marital Status (Married). The variable marital status addressed are you now married, widowed, divorced, or separated, or have you never been married? This measure utilizes four levels: (1) married, (2) widowed, (3) divorced or separated, and (4) never been married. The marital status variable was recoded into (1) married and (0) not married. 


\section{Data Analysis Plan}

The analysis plan for the current dissertation took place in a series of steps to answer the hypotheses for the current study. All of the analyses for this dissertation were completed using SPSS 25 . The hypotheses for the current dissertation include:

H1: Veterans who experience strain (unemployment) will be more likely to engage in binge drinking than those who did not experience unemployment. $\mathrm{H} 2$ : Veterans who experienced strain (combat) will be more likely to engage in binge drinking than veterans who did not experience combat.

H3: Binge drinking will increase with veterans who experience negative emotions (depression).

H4: The likelihood of engaging in binge drinking will increase veterans who experience health issues.

H5: I expect biological sex, age and marital status differences in binge drinking among veterans.

The first step is the presentation of the univariate statistics to provide a brief description of the sample and to provide some indication of whether variation is present. In general, the mean is used to provide the average of the variable of interest (Martinez \& Bartholomew, 2017). This occurs when the variable is, at least, ordinal. That is, when the variable is coded as ordinal the mean category can be interpreted. The mean is best suited for variables that are interval or ratio level. In the instances, when the variable is 
coded in a dichotomous manner, the mean may be interpreted as a percentage. In general, the standard deviation is an estimate of the average variability of a set of data measured in the same units of measurement as the original data and is the square root of the variance (Martinez \& Bartholomew, 2017). The standard deviation is, generally, applicable to variables that have been coded as ordinal or above.

The second step is a presentation to the bivariate statistics. In this dissertation, Pearson correlations were used to demonstrate whether the measures share variation Allen, 2017). According to Mukaka (2012) the shared variation between two variables can be from -1 for a negative correlation and $a+1$ for a positive correlation. When the correlation coefficient is a positive number, as one variable's variation increases another variable's variation increases. If the number is a negative number, then one variable's variation is increasing but the other variable's variation is decreasing. Mukaka (2012) explained that stronger shared variance is indicated by the correlation coefficient being closer to 1 or -1 .

The third step of the analysis plan was the presentation of multivariate analysis. The multivariate analysis consisted of logistic regression, which can predict categorical outcomes based on predictor variables (Sperandei, 2014). Garson (2011) argued there are several instances when logistic regression can be used: (1) to predict categorical dependent variable on the continuous and/or categorical independent variables, (2) to determine the effect size of the independent variable on the dependent (i.e., the odds 
ratio), (3) to rank the independent variables on relative importance, (4) to measure interaction effects and (5) to understand the impact of covariate control variables. In this dissertation logistic regression was used because the dependent variable was categorical (i.e., dichotomous), the odds ratio is an important for effect size, and it will allow for an understanding of the impact of other control variables.

In any use of any form of regression, multicollinearity is a potential issue. Multicollinearity generally occurs when there are at least two highly correlated independent variables that are assessed simultaneously in a regression model (Vatcheva, Lee, McCormick, Rahbar, 2016). Multicollinearity can be identified through tolerance and reciprocal, called variance inflation factor. Multicollinearity is problematic when tolerance is less than 0.2 .

If multicollinearity is present, there are ways to reduce collinearity, such as eliminating one or more independent variables that are highly correlated with another independent variable (O’brien, 2007). However, in doing so this would potentially change the theoretical context of the dissertation. Another way to achieve this would be to combine variables that may be similar to one another. Combining two similar measures would solve the collinearity problem created by the high correlation between two variables, this also gives a more reliable estimate (O’brien, 2007).

The fourth step of the analysis plan is the sensitivity analysis. Sensitivity analysis is used to examine the extent to which the results are affected by changes in the methods 
and models. Sensitivity analysis is defined as "a method to determine the robustness of an assessment by examining the extent to which results are affected by changes in methods, models, values of unmeasured variables, or assumptions" (Thabane et al., 2013, p. 2). Using data from a second subsample (i.e., only veterans with combat experience) to examines the hypotheses of this dissertation sought to examine whether the robust nature of the results from the veterans only sample. To clarify, the hypotheses for this dissertation based on the assumptions from Agnew's (1992) GST and binge drinking among military veterans with combat experience will be examined.

This chapter described data collection methodology, the sample, variables, and data analytic plan to investigate the study's research hypotheses. The following chapter will provide descriptive statistics of the sample, the correlations, and the results from the logistic regression models. 


\section{CHAPTER V \\ RESULTS}

The preceding chapter explained the methodology and analytic approach undertaken to examine the hypotheses that were presented in Chapter 3. Chapter 5 will present and interpret the results of the statistical analysis. The remainder of this chapter will follow the steps that were presented in the analytic plan, which will include the descriptive statistics, bivariate correlations, logistic regression and OLS logistic regression. This chapter will be presented in two parts. The first part will present the results of the veteran sample. The second part will present the results from a subset of the veteran sample who experienced combat.

\section{Step 1}

The first step of the analysis plan is the presentation of descriptive statistics for the variables used in the current dissertation analysis from the veterans only sample ( $n=962)$. Descriptive statistics for the sample of military veterans for the survey years of 2015-2017 for the current dissertation are included in Table 1. 
Among veterans, 22.87 percent of the sample binge drank within the past 30 days. Four percent of the veteran sample was unemployed. Of the veteran sample, 47 percent stated that they experienced combat. The average for the health measure for veterans was "very good" $($ mean $=2.20, \mathrm{SD}=0.86)$.

Table 1. Descriptive Statistics Veteran Sample ( $n=962)$.

\begin{tabular}{|l|l|l|l|l|}
\hline Variable & & Totals & & \\
\hline & Percentage/Mean & St. dev. & Min & Max \\
\hline Binge Drinking & $23 \%$ & -- & 0.00 & 1.00 \\
\hline Unemployed & $4 \%$ & -- & 0.00 & 1.00 \\
\hline Combat & $47 \%$ & -- & 0.00 & 1.00 \\
\hline Poor Health & 2.20 & 0.86 & 1.00 & 4.00 \\
\hline Depression & $13 \%$ & -- & 0.00 & 1.00 \\
\hline Income & 3.21 & 0.96 & 1.00 & 4.00 \\
\hline Age & 3.70 & 0.56 & 1.00 & 4.00 \\
\hline Female & $13 \%$ & -- & 0.00 & 1.00 \\
\hline White & $73 \%$ & -- & 0.00 & 1.00 \\
\hline Married & $68 \%$ & -- & 0.00 & 1.00 \\
\hline
\end{tabular}

The depression measure indicated that $13 \%$ of the veteran sample had a depressive episode in their lifetime. The average income (mean $=3.21, \mathrm{SD}=0.96$ ) of the veteran sample was the $\$ 50,000-\$ 74,999$ category. The average age of the veteran sample was 35 and older $($ mean $=3.70, \mathrm{SD}=0.56)$. The results indicated that $13 \%$ of the veteran sample are women. Seventy three percent of the veteran sample was white. Finally, 68 percent of the veteran sample was married.

Figure 1 presents the line graph results of veteran binge drinking within the past 30 days by year. The research findings indicated that binge drinking behaviors within the 
past 30 days decreased from 2015-2017 in veterans. Figure 1 indicates in 2015, 16\% of non-combat veterans participated in binge drinking within the past 30 days. In 2016, there was a slight decrease in binge drinking behaviors to $15 \%$. In 2017 , a further decrease in binge drinking in the past 30 days was reported at $13 \%$.

Figure 1: Line Graph Binge Drinking in Veterans ( $n=962)$.

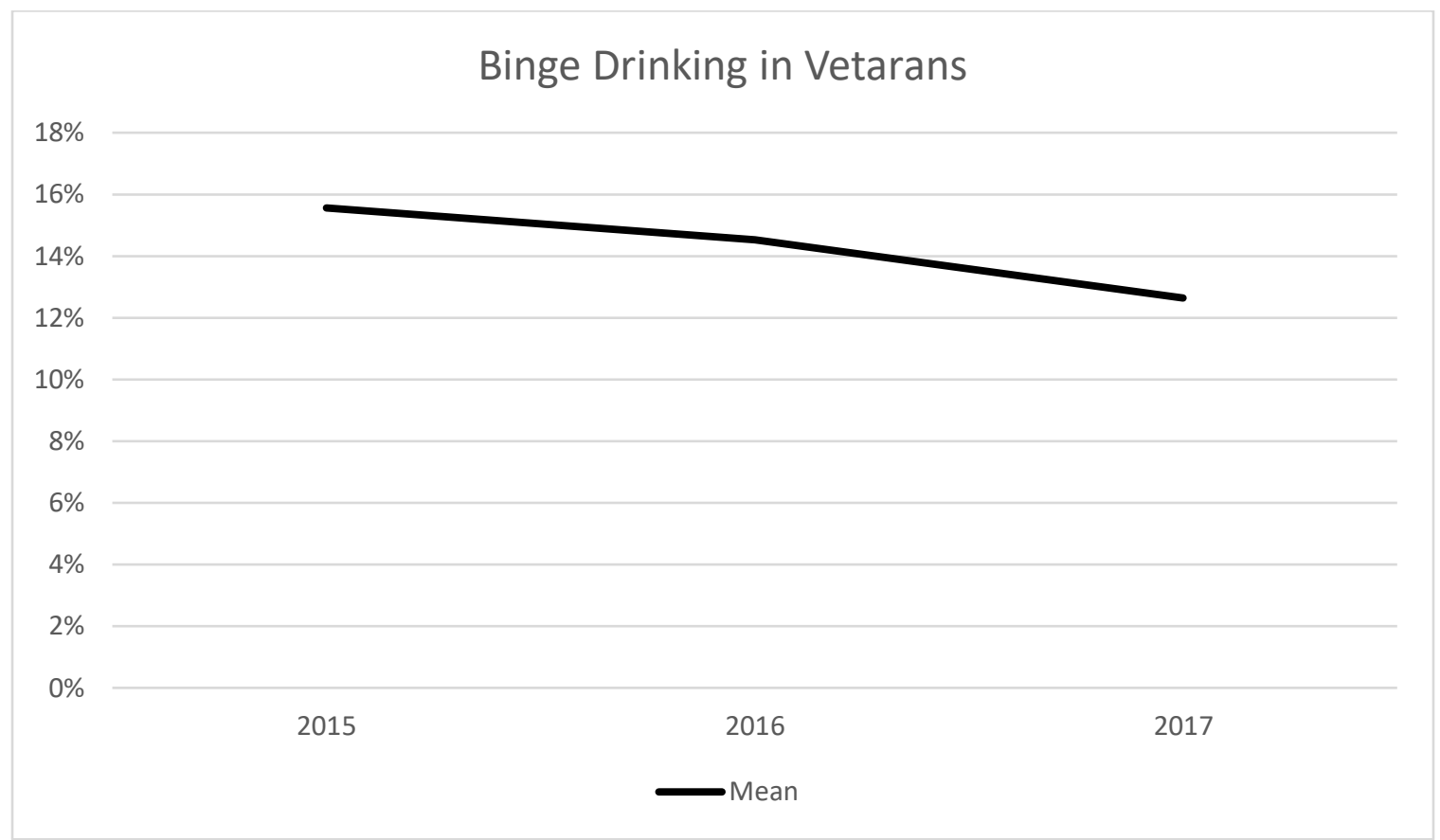




\section{Step 2}

Table 2 presents the bivariate correlations for the sample of veterans. Within the veteran sample, four of the independent variables were significantly associated with the dependent variable, binge drinking. 
Table 2: Bivariate Correlations between Variables in the Veteran Sample $(n=962)$.

\begin{tabular}{|c|c|c|c|c|c|c|c|c|c|c|}
\hline & $\begin{array}{l}\text { Binge } \\
\text { Drink }\end{array}$ & Unemployed & Combat & $\begin{array}{c}\text { Poor } \\
\text { Health }\end{array}$ & Depression & Age & Female & White & Income & Married \\
\hline (1) & 1.00 & & & & & & & & & \\
\hline (2) & -0.10 & 1.00 & & & & & & & & \\
\hline (3) & -0.14 & -0.02 & 1.00 & & & & & & & \\
\hline (4) & $-0.39 *$ & -0.05 & -0.01 & 1.00 & & & & & & \\
\hline (5) & -0.08 & -0.05 & -0.03 & -0.06 & 1.00 & & & & & \\
\hline$(6)$ & $-0.74 *$ & 0.03 & 0.05 & -0.05 & 0.03 & 1.00 & & & & \\
\hline (7) & -0.13 & 0.03 & 0.10 & 0.00 & -0.17 & 0.06 & 1.00 & & & \\
\hline$(8)$ & $-0.21 *$ & 0.04 & 0.12 & 0.06 & -0.09 & 0.03 & 0.07 & 1.00 & & \\
\hline$(9)$ & $-0.25^{*}$ & 0.10 & -0.12 & 0.10 & 0.08 & $-0.23^{*}$ & -0.04 & -0.13 & 1.00 & \\
\hline (10) & 0.06 & 0.04 & -0.01 & 0.01 & 0.09 & -0.10 & 0.06 & -0.04 & -0.34 & 1.00 \\
\hline
\end{tabular}

*Statistical significance at the .05 level

(1) Binge Drink, (2) Unemployed, (3) Combat, (4) Poor Health, (5) Depression, (6) Age, (7) Female, (8) White, (9) Income (10) Married 
A negative and significant correlation was found between the dependent variable, binge drinking and health, age, race and income. As a veteran's health becomes worse their binge drinking in the past 30 days decreases with a moderate negative relationship $(\mathrm{r}=-.39, \mathrm{p}=.05)$. As a veteran's age increases their binge drinking in the past 30 days decreases with a strong negative relationship $(\mathrm{r}=-.74, \mathrm{p}=.05)$. In the sample of veterans, whites binge drink with a weak negative relationship $(r=-.21, \mathrm{p} .05)$. As a veteran's income increases their binge drinking in the past 30 days decreases with a weak negative relationship $(\mathrm{r}=-.25, \mathrm{p}=.05)$.

\section{Step 3}

Table 3 presents results from logistic regression analysis of our demographic variables and strain variables as explanatory factors of participation in binge drinking in the past 30 days within the sample of military veterans. 
Table 3: Binomial Logistic Regression Analysis for Veterans ( $\mathrm{n}=962)$.

\begin{tabular}{|l|l|l|l|l|l|l|l|}
\hline Item & B & S.E & p-value & OR & $\begin{array}{l}\text { 95\% } \\
\text { Conf. } \\
\text { Interval } \\
\text { LL }\end{array}$ & UL & Tolerance \\
\hline Unemployed & -0.06 & 0.39 & 0.87 & 0.94 & 0.43 & 2.03 & 0.97 \\
\hline Combat & 0.08 & 0.16 & 0.63 & 1.08 & 0.79 & 1.48 & 0.97 \\
\hline Poor Health & 0.01 & 0.09 & 0.91 & 1.01 & 0.84 & 1.21 & 0.97 \\
\hline Depression & -0.35 & 0.25 & 0.16 & 0.70 & 0.43 & 1.15 & 0.93 \\
\hline Age & $-0.59^{*}$ & 0.14 & 0.00 & 0.55 & 0.42 & 0.72 & 0.90 \\
\hline Female & 0.17 & 0.23 & 0.45 & 1.19 & 0.76 & 1.87 & 0.95 \\
\hline White & -0.25 & 0.18 & 0.15 & 0.78 & 0.55 & 1.10 & 0.95 \\
\hline Income & -0.02 & 0.09 & 0.85 & 0.98 & 0.82 & 1.18 & 0.75 \\
\hline Married & $-0.51^{*}$ & 0.18 & 0.00 & 0.60 & 0.42 & 0.85 & 0.81 \\
\hline & & & & & & & \\
\hline Fit Statistics: & & & & & & & \\
\hline Chi-square & $43.96^{*}$ & & & & & & \\
\hline -2 Loglikelihood & 990.55 & & & & & & \\
\hline Cox \& Snell r-square & 0.05 & & & & & & \\
\hline Nagelkerke r-square & 0.07 & & & & & & \\
\hline
\end{tabular}

$\mathrm{p}<.00 * ; \mathrm{LL}=$ Lower Limit, UL = Upper Limit

This dissertation intended to study five hypotheses, but only one hypothesis was partially supported in the veterans only sample. The results indicated that two measures had significant links with binge drinking in the past 30 days: age and marital status. Specifically, as age increases, the odds of binge drinking within the past 30 days are $45 \%$ less likely to occur $(b=-.59$, odds ratio $=.55$, $\mathrm{p}$-value 0.00$)$. The odds of married veterans are $40 \%$ less likely to binge drink in the past 30 days than non-married veterans $(b=-.51$, odds ratio $=.60$, $p$-value $=0.00$ ). This is partially consistent with Calhoun et al., (2016), findings that there were significant associations between frequent binge drinking and age, 
and marital status in a sample of veterans. Research found that age of veterans is associated with increased binge drinking episodes (Cucciare et al., 2011).

In any form of regression, multicollinearity among the independent measures is a concern. To address this concern, the tolerance of each independent measure was examined. None of the tolerance coefficients were near the .20 level. These results indicate that multicollinearity is not a problem in these data.

While multicollinearity is not a problem with these data, it is possible that combat experience used as a variable may be masking some of the results for in this dissertation. With this in mind, sensitivity analyses of the data required that a subsample of the veteran data be used, specifically veterans with combat experience $(n=453)$. The remainder of this chapter will describe the univariate statistics, bivariate statistics and multivariate statistics via logistic regression analysis from this subsample.

\section{Step 1}

The descriptive statistics present the distribution of the data for the variables in the study in the subset of veterans that experienced combat (i.e., strain with employment, health, depression, and income with binge drinking in the past 30 days). Table 4 presented the descriptive statistics of the veterans that had combat experience. Among veterans with combat experience, 24 percent of the sample binge drank within the past 30 days. Four percent of the combat veteran sample was unemployed. The measure of health for combat veterans was "very good" (mean=2.22, $\mathrm{SD}=0.87)$. 
Table 4. Descriptive Statistics Veteran with Combat Sample $(n=453)$.

\begin{tabular}{|l|l|l|l|l|}
\hline Variable & & Totals & & \\
\hline & Percentage/Mean & St. dev. & Min & Max \\
\hline Binge Drinking & $24 \%$ & -- & 0.00 & 1.00 \\
\hline Unemployed & $4 \%$ & -- & 0.00 & 1.00 \\
\hline Poor Health & 2.22 & 0.87 & 1.00 & 4.00 \\
\hline Depression & $13 \%$ & -- & 0.00 & 1.00 \\
\hline Income & 3.30 & 0.91 & 1.00 & 4.00 \\
\hline Age & 3.68 & 0.53 & 1.00 & 4.00 \\
\hline Female & $9 \%$ & -- & 0.00 & 1.00 \\
\hline White & $69 \%$ & -- & 0.00 & 1.00 \\
\hline Married & $69 \%$ & -- & 0.00 & 1.00 \\
\hline
\end{tabular}

The depression measure indicated that $13 \%$ of the combat sample had a depressive episode in their lifetime. The average income (mean $=3.30, \mathrm{SD}=0.91)$ of the combat sample was the $\$ 50,000-\$ 74,999$ category. The average age of the veteran sample was 35 and older (mean $=3.68, \mathrm{SD}=0.53)$. The results indicated that $9 \%$ of the combat veteran sample are women. Sixty nine percent of the combat veteran sample was white. Finally, 69 percent of the combat veteran sample was married.

Figure 2 presents the line graph results of combat veteran binge drinking in the past 30 days by year. The results for veterans who did experience combat indicated a decrease in binge drinking in the past 30 days from 2015 to 2017 is presented in figure 2 . In $2015,18 \%$ of veterans reported binge drinking in the past 30 days. Binge drinking in the past 30 days further decreased to $15 \%$ in 2016 . Finally, in 2017 the results stayed 
consistent with slightly over $15 \%$ of veterans reporting binge drinking in the past 30 days.

Figure 2: Line Graph Binge Drinking in Veterans with Combat Exposure $(n=453)$.

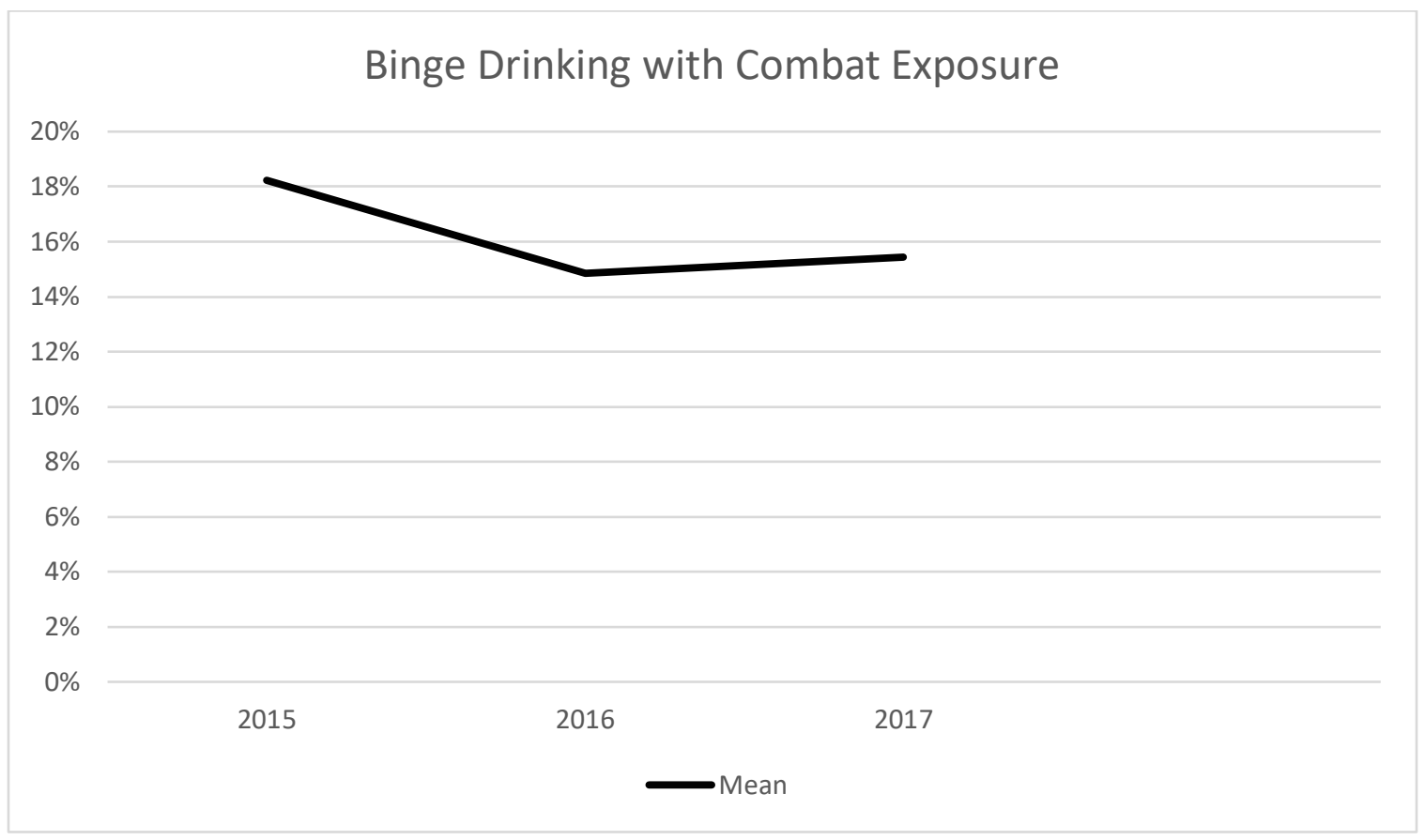

\section{Step 2}

The second step of the analysis plan is the interpretation the bivariate analysis between the dependent variable and the independent variables in the sub sample of combat veterans. The bivariate analysis used Pearson's correlation coefficient, which shows the strength of the relationship between the dependent and independent variables. Table 5 presents the bivariate correlations for the sample of combat veterans. Within the 
combat veteran sample, four of the independent variables were significantly associated with the dependent variable, binge drinking. 
Table 5: Bivariate Correlations between Variables in the Combat Veteran Sample $(n=453)$

\begin{tabular}{|l|l|l|l|l|l|l|l|l|l|}
\hline & $\begin{array}{l}\text { Binge } \\
\text { Drink }\end{array}$ & Unemployed & $\begin{array}{c}\text { Poor } \\
\text { Health }\end{array}$ & Depression & Age & Female & White & Income & Married \\
\hline$(1)$ & 1.00 & & & & & & & & \\
\hline$(2)$ & $-0.20^{*}$ & 1.00 & & & & & & & \\
\hline$(3)$ & $-0.29^{*}$ & -0.07 & 1.00 & & & & & & \\
\hline$(4)$ & -0.06 & 0.01 & -0.10 & 1.00 & & & & & \\
\hline$(5)$ & $-0.78^{*}$ & 0.15 & -0.09 & -0.02 & 1.00 & & & & \\
\hline$(6)$ & -0.15 & 0.03 & 0.00 & -0.12 & 0.11 & 1.00 & & & \\
\hline$(7)$ & -0.17 & -0.02 & 0.04 & -0.08 & 0.06 & 0.10 & 1.00 & & \\
\hline$(8)$ & $-0.24^{*}$ & 0.09 & 0.03 & 0.11 & $-0.22^{*}$ & -0.06 & -0.13 & 1.00 & \\
\hline$(9)$ & -0.07 & 0.08 & 0.01 & 0.12 & 0.02 & 0.09 & -0.03 & -0.32 & 1.00 \\
\hline
\end{tabular}

*Statistical significance at the .05 level 
A negative and significant association was found between the dependent variable, binge drinking and unemployment, health, age and income. In the sample of combat veterans, unemployed veterans binge drink with a weak negative relationship $(\mathrm{r}=-.20$, $\mathrm{p}=.05$ ). As a veteran's health improved their binge drinking in the past 30 days decreases with a weak negative relationship $(r=-.29, \mathrm{p}=.05)$. As a veterans age increases their binge drinking in the past 30 days decreases with a strong negative relationship $(r=-.78, p=.05)$. As a veteran's income increases their binge drinking in the past 30 days decreases with a weak negative relationship $(\mathrm{r}=-0.24, \mathrm{p}=.05)$.

\section{Step 3}

The third step in the analysis plan involves multivariate analysis using logistic regression analysis in the subsample of combat veterans via SPSS. Table 6 presents results from logistic regression analysis. 
Table 6: Binomial Logistic Regression Analysis for Combat Veterans

\begin{tabular}{|l|l|l|l|l|l|l|l|}
\hline Item & B & S.E & p-value & OR & $\begin{array}{l}\text { 95\% } \\
\text { Conf. } \\
\text { Interval } \\
\text { LL }\end{array}$ & UL & Tolerance \\
\hline Unemployed & 0.27 & 0.53 & 0.61 & 1.31 & 0.46 & 3.73 & 0.94 \\
\hline Poor Health & 0.09 & 0.13 & 0.51 & 1.09 & 0.84 & 1.42 & 0.97 \\
\hline Depression & $-0.80^{*}$ & 0.40 & 0.05 & 0.45 & 0.21 & 0.99 & 0.93 \\
\hline Age & $-0.66^{*}$ & 0.21 & 0.00 & 0.52 & 0.34 & 0.78 & 0.90 \\
\hline Female & 0.21 & 0.37 & 0.58 & 1.23 & 0.59 & 2.56 & 0.95 \\
\hline White & $-0.49^{*}$ & 0.24 & 0.04 & 0.62 & 0.38 & 0.99 & 0.97 \\
\hline Income & -0.15 & 0.13 & 0.27 & 0.86 & 0.66 & 1.12 & 0.79 \\
\hline Married & -0.28 & 0.26 & 0.28 & 0.76 & 0.45 & 1.26 & 0.84 \\
\hline & & & & & & & \\
\hline Fit Statistics: & & & & & & & \\
\hline Chi-Square & $28.50^{*}$ & & & & & & \\
\hline -2 Loglikelihood & 466.78 & & & & & & \\
\hline Cox \& Snell r-square & 0.06 & & & & & & \\
\hline Nagelkerke r-square & 0.09 & & & & & & \\
\hline
\end{tabular}

$\mathrm{p}<.05^{*} ; \mathrm{LL}=$ Lower Limit, UL $=$ Upper Limit

This dissertation intended to study five hypotheses, but only two hypotheses were supported in the data. Hypothesis 3, binge drinking will increase with veterans who experience negative emotions (depression) and hypothesis 5, I expect gender and age differences in binge drinking among veterans. The results indicated that three measures had significant links with binge drinking: depression, age, and white. Specifically, as depression increases, binge drinking within the past 30 days are 55\% less likely to occur $(\mathrm{b}=-.80$, odds ratio $=.45$, $\mathrm{p}$-value $=0.05)$. As age increases, the odds of binge drinking within the past 30 days are $48 \%$ less likely to occur $(b=-.66$, odds ratio $=.52$, pvalue $=0.00$ ). The odds of white veterans are $38 \%$ less likely to binge drink in the past 30 
days than non-whites $(b=-.49$, odds ratio $=.62, p$-value $=0.04)$. This consistent with research which found that race and age is associated with increased binge drinking episodes in veterans (Calhoun et al., 2016; Cucciare et al., 2011). The current results are consistent with the literature that indicates binge drinking is associated with depression (Whiteman \& Barry, 2011, Bucher, 2011, McDevitt-Murphy et al., 2010). Results are consistent with GST that strain results in negative emotions (i.e., depression) which further leads to an attempt to correct their strain through a beneficial coping mechanism, such as emotional coping (i.e., binge drinking).

In any form of regression, multicollinearity among the independent measures is a concern. To address this concern, the tolerance of each independent measure was examined. None of the tolerance coefficients were near the .20 level. These results indicate that multicollinearity is not a problem in this subsample of these data. The next chapter discusses the impact of the current study on the theory and practice including potential policy implications. 


\section{CHAPTER VI}

\section{DISCUSSION}

The current dissertation analyzed survey data from a subsample from the NSDUH that was specific to military veterans to provide a partial study of Agnew's (1992) General Strain Theory (GST). The hypotheses of the current dissertation are that experiences of strain (i.e., work status, combat, health and depression) will be associated with binge drinking.

In the veteran only sample, the results do not indicate that specific measures of GST have a link with binge drinking. This is not consistent with the hypotheses in this dissertation, nor is it consistent with the existing literature that has examined this connection before with health (Olenick et al., 2015), depression (Sheffler et al., 2016) income (Calhoun et al., 2016) and employment (MacLean, 2010) and binge drinking.

Regarding the second part of the dissertation findings, combat exposure in military veterans, studies have shown that veterans who experienced combat are more likely to engage in binge drinking (Ciarleglio et al., 2018; Hoopsick et al., 2018). Further, combat exposure is also significantly associated with higher rates of depression (Sheffler, Ryshing, Stanley, \& Ericsson, 2016). Previous research also identified depression and age being associated with binge drinking in veterans with combat exposure (Bradley et al., 2001; Ciarleglio et al., 2018; Cucciare et al., 2011). Calhoun et al., (2016) found associations between frequent binge drinking and race. The results of this did not provide 
support for these findings. In fact, the results indicated that those that experienced a major episode of depression in their lifetime were less likely to binge drink.

Three explanations may be helpful in understanding these results. First, the data used for this study come from a large national data set. While these types of data have some advantages (e.g., large and often generalizable), these data were not collected with the intention of this type of analysis. This means that these data were not designed to target veterans and may not be representative of those veterans that binge drank. In other words, those veterans that may be experiencing these types of strains may not be inclined to complete this type of national survey excluding them from the data. This could suggest the link between strain measures may be present in a better sample of veterans, but it does not appear it is present in these data.

Second, the measures that were used for these data were proxy measures. These measures do not all for maximum coverage of the types of strains. For example, the depression measure, while vast in its item coverage, was reduced by the NSDUH to a dichotomy of whether the individual - that happens to be a veteran in this dissertationhad a major depressive episode in their lifetime. A major depressive episode in their lifetime could be rare. In fact, in these data, only 13 percent of the sample had a major depressive episode in their lifetime. With such a small amount of major depressive episodes, reason dictates that the link with binge drinking may be tenuous at best, and this partially attributed this non-statistically significant finding. The veterans and the 
veterans with combat experience do not seem to experience high levels of the other strains as well.

The third reason for these results is that binge drinking may not be activity of interest for the veterans to cope with the strains and depression that they could be experiencing. It is possible that other drugs may be used. For instance, it is possible that the strain measures among this veteran sample may be related marijuana or cocaine use. In other words, the hypotheses and veteran sample may yield supportive results with other forms of drug use. This is likely the issue when it comes to the inverse connection between depression and binge drinking. In this study, the results showed that as the veterans with combat experience had a depressive episode they are less likely to binge drink. This is because they may be more likely to choose a different drug.

\section{Policy Implications}

The connection between veterans and binge drinking is vital as more military individuals are retiring from the military and reacclimating back into society (Bucher, 2011; Washington et al., 2010; MacLean, 2010). Strain experienced by military veterans provides many opportunities for emotional coping, such as binge drinking (Dove \& Joseph, 2007; Najavits, 2002; Bradley et al., 2001). Policy implications should be directed towards military veterans with the goal of reducing behaviors like binge drinking. 
Several programs and policies exist with an intent to educate and help military veterans who have substance use issues and binge drinking issues. However, programs for veterans are very limited. The current dissertation's findings emphasize the need for programs designed specifically for targeting military veteran's needs. Furthermore, programs designed to aid in the development of positive coping mechanisms and a reduction on emotional coping such as substance use and binge drinking.

For example, the Confidential Alcohol Treatment and Education Pilot is a promising initiative that allows for active duty service members to receive confidential treatment (Gibbs \& Olmstead, 2011). The program was implemented in 2009 and is designed for soldiers to receive treatment before they have an alcohol-related incident. The program started three military installations in 2009 and expanded to six. Program eligibility criteria exclude soldiers that are seeking treatment or testing positive for illicit drug use, those who are command referred, and those in certain occupational specialties (Department of Defense, 2004). Research found that participants of the program would not have sought treatment without the option of confidentiality (Gibbs \& Olmsted, 2011). Participants indicated that confidentiality made it easier to remain engaged in treatment (Cooper et al., 2003).

Another example is group therapy, marital and family therapy, case management and pharmacotherapy. According to Stinchfield, Owen \& Winters (1994), group therapy is the most common treatment and provides support, improves awareness for triggers, 
teaches healthy relationship skills and addresses mental health problems (Stinchfield, Owen \& Winters, 1994; Najavits, 2002). Group therapy is a common treatment in the Veterans Health Administration system which enables more efficient service delivery for soldiers with PTSD (Kracen, Mastnak, Loaiza \& Matthieu, 2013). According to the National Center for PTSD, group treatment formats are available for PTSD treatment such as Cognitive Processing Therapy (CPT) and Prolonged Exposure (PE). Group treatments normally consist of twelve, ninety-minute sessions. Upon completing treatment, participants report significant reductions in PTSD severity (Sloan \& Beck, 2016).

Case management can help with the multiple needs of veterans with substance use issues, such as binge drinking (Najavits, 2002). According to Veterans Resource Center, a case manager is a veteran's main point of contact to help provide information and plan a course of action to achieve their goals by connecting veterans to the correct resources. The purpose of a case manager is to work in collaboration with veterans to help develop a service plan for barriers and goals related to substance abuse, mental health, medical needs, finances, education, employment, and housing. Veterans meet with their case manager on a regular basis as a way to provide additional support or assistance. The main goal is to help veterans achieve and maintain independence (Veterans Resource Center, 2019). 
Pharmacotherapy can help treat withdrawal symptoms, help with relapse prevention and prevention as well as management (Lingford-Hughes, Welch \& Nutt, 2004). In 2006 the FDA approved pharmacotherapy for the Veteran Health Administration. Approximately $2.8 \%$ VHA patients with clinically diagnosed alcohol use orders received pharmacotherapy in 2006 (Harris, Oliva, Bowe, Humphreys, Kivlahan, \& Trafton, 2012). Pharmacotherapy can include the use of selective serotonin reuptake inhibitors (SSRIs) sertraline (Zoloft, Pfizer) and paroxetine HCI (Paxil, GlaxoSmithKline) (Alexander, 2012). Each of the medications are used to treat some sort of mental health diagnosis such as depression and PTSD.

There are several treatment opportunities for military personnel and veterans such as TRICARE. TRICARE is a health care program for uniformed service members and veterans, their families and dependent persons, members of the National Guard and Reserve. This health care program is managed by the Defense Health Agency under the Department of Defense and provides insurance coverage for health plans, special programs, prescriptions and dental plans. This program also covers mental health care services which include acute inpatient psychiatric care, applied behavioral analysis, partial hospitalization and treatment for any psychological problems. TRICARE provides individuals with access for treatments such as detoxification, rehabilitation and general therapy as well as pharmacy programs that supplies prescription medications (Pieper, 2004). 
Furthermore, as participation in binge drinking continues in veterans, the Department of Veterans Affairs (VA) services provides treatment programs specifically for substance use problems. The substance use programs target military veterans who have problems with alcohol, tobacco, or drugs. Treatment addresses all types of problems that are associated with substance use, such as unhealthy use of alcohol to life-threatening conditions. Treatment can include the use of medications for treatment, or other option such as therapy. Medications can be used to treat alcohol dependence and therapy is used to help improve their skills for dealing with triggers and relapse (Veteran Affairs, 2019).

\section{Limitations}

Although there were few significant findings, they remain meaningful. The current dissertation has several limitations. First, with all survey research, limitations will come from utilizing an existing dataset in terms of sample size and design which may limit the accuracy of the estimates. As outlined above, these data were not designed for this study, but they were designed to examine the epidemiology of substance use in general. The use of many pre-existing measures provides issues with missing data, a large margin of sampling error and the limited number of cases.

Second, the current study is also quantitative in nature, meaning it is difficult to get an accurate representation of the data. This dissertation is lacking in a qualitative lens and the veteran's meanings of the strains. A third limitation of the study only focused on three years-- 2015-2017, which may play a factor in the type of substances that are used 
by veterans. As stated earlier, binge drinking behaviors may not be the substance of choice for veterans in those years; however, other substances might be. Also, binge drinking was measured only in the past 30 days could potentially obtain different results at different times of the year. Fourth, the data is cross-sectional making causal inferences between veterans' participation in binge drinking difficult. This causal relationship may be established by calling on future research to implement longitudinal (i.e., the current data are concatenation of multiple cross-sectional studies) and experimental designs.

As mentioned earlier, due to data limitations, many options to create valid measures of strain were not possible in these data. Lastly, it is hard to address whether strain is related specifically to a veteran's time in the military, or another potentially strenuous job such as firefighter, police officer, law enforcement, etc. making it difficult to address the timeline of when the stress occurred.

Despite the limitations, the current dissertation shows the current strain measures do not have significant links with binge drinking for veterans. In the context of veterans with combat experience, the results indicate that major depressive episodes in their lifetime decreases the likelihood of binge drinking. This result does not support GST, but there are reasons this occurs. The reasons range from the measurements of GST, the data not being designed for this study, and the possibility that other drugs may be used instead. Future studies that correct for these issues as well as use longitudinal or qualitative data that are specific to veterans will be helpful. Until this occurs, the results 
of the present study indicate that these GST measures in these data do not have a link with binge drinking. 


\section{REFERENCES}

38 CFR 3.1(d)). Definitions. Electronic Code of Federal Regulation. Department of Veteran Affairs.

Agnew, R. (1987). On "testing structural strain theories." Journal of Research in Crime and Delinquency, 24(4), 281-286.

Agnew, R. (1992). Foundation for General Strain Theory of Crime and Delinquency. Criminology, 30(1), 47-88.

Agnew, R. (2001). Building on the Foundation of General Strain Theory: Specifying the Types of Strain Most Likely to Lead to Crime and Delinquency. Journal of Research in Crime and Delinquency, 38(4), 319-361.

Agnew, R. (2002). Experienced, vicarious, and anticipated strain: An exploratory study on physical victimization and delinquency. Justice Quarterly, 19(4), 603-632.

Agnew, R. (2006). General Strain Theory: Current Status and Directions for Further Research. In F. T. Cullen, J. P. Wright, \& K. R. Blevins (Eds.), Advances in criminological theory: Vol. 15. Taking stock: The status of criminological theory (101-123). Transaction Publishers.

Agnew, R. (2012). Reflection on "A Revised Strain Theory of Delinquency”. Social Forces, 91(1), 33-38 
Agnew, R., Brezina, T., Wright, J. P., \& Cullen, F. T. (2002). Strain, personality traits, and delinquency: Extending general strain theory. Criminology, 40, 43-71.

Agnew, R., \& White, H. R. (1992). An Empirical Test of General Strain Theory. Criminology, 30, 475-499.

Ahmadi, H., \& Green, S.L. (2011). Screening, brief intervention, and referral to treatment for military spouses experiencing alcohol and substance use disorders: A literature review. Journal of Clinical Psychology in Medical Settings, 18(2), 129-136.

Alexander, W. (2012). Pharmacotherapy for Post-traumatic Stress Disorder in Combat Veterans: Focus on Antidepressants and Atypical Antipsychotic Agents. $P \& T, 37$, $32-38$.

Allen, J. P., Crawford, E. F., \& Kudler, H. (2016). Nature and Treatment of Comorbid Alcohol Problems and Post-Traumatic Stress Disorder Among American Military Personnel and Veterans. Alcohol Research: Current Reviews, 38(1), 133-140.

Allen, M. (2017). Simple Bivariate Correlation. The SAGE Encyclopedia of Communication Research Methods.

Ames, G., \& Cunradi, C. (2004). Alcohol use and preventing alcohol-related problems among young adults in the military. Alcohol Research \& Health, 28, 252-257.

American Psychiatric Association. Diagnostic and Statistical Manual of Mental Disorders (DSM-5), Fifth edition. 2013.

Anthony, J. C., Warner, L. A., \& Kessler, R. C. (1994). Comparative epidemiology of dependence on tobacco, alcohol, controlled substances, and inhalants: Basic 
findings from the National Comorbidity Survey. Experimental and Clinical Psychopharmacology, 2(3), 244-268

Aponte, M., Balfour, F., Garin, T., Glasgow, D., Lee, T., Thomas, E., \& Williams, K. (2017).America's Women Veterans: Military Service and VA Benefit Utilization Statistics. Women's Veteran Statistics, National Center for Veteran Analysis and Statistics.

Bachman, J. G., O'Malley, P. M., Schulenberg, J. E., Johnston, L. D., Bryant, A. L., \& Merline, A. C. (2002). Research monographs in adolescence. The decline of substance use in young adulthood: Changes in social activities, roles, and beliefs. Lawrence Erlbaum Associates Publishers.

Bader, G., Ragsdale, K. G., \& Franchina, J.J. (2001). Screening for mental illness in a Veteran Affairs Women's health clinic. Psychiatric Service, 52(11), 1521-1522.

Baker, T. B., Piper, M. E., MCarthy, D. E., Majeskie, M. R., \& Fiore, M.C. (2004). Addiction motivation reformulated: an affective processing model of negative reinforcement. Psychological Review, 111(11), 33-51.

Bareis, N., \& Mezuk, B. (2016). The relationship between childhood poverty, military service, and later depression among men: Evidence from the Health and Retirement Study. Journal of Affective Disorder, 206, 1-7. 
Bartlet, B., Smith, L. J., Tran, K. K., \& Vujanovic, A. A. (2018). Understanding mental health among military veterans in the fire service. Psychiatry Research, 267, 394 399.

Bergen-Cico, D. K., (2012). War and Drugs: The Role of Military Conflict in the Development of Substance Abuse. Boulder, CO: Paradigm Publishers.

Berry, K. J., Johnston, J. E., \& Mielke, P. W. (2009). Nominal-Ordinal Measures of Association: A comparison of two measures. Perceptual and Motor Skills, 109(1), 285-294

Boden, T. M., Kimerling, R., Kulkrani, M., Bonn-Miller, M. O., Weaver, C., \& Trafton, J. (2014). Coping among military veterans with PTSD in substance use disorder treatment. Journal of Substance Abuse Treatment, 47(2), 160-167.

Bradley, K. A., Bush K. R., Davis T. M., Dobie, D. J., Burman, M. L., Rutter, C. M., \& Kivlahan, D. R. (2001). Binge drinking among female Veteran Affairs patients: prevalence and associated risk. Psychology of Addictive Behavior, 15(4), 297-305.

Bray R. M., Brown, J. M., \& Williams, J. (2013). Trends in binge and heavy drinking, alcoholrelated problems, and combat exposure in the U.S. military. Substance Use Misuse, 48(10), 799-810.

Bray, R. M., Fairbank, J. A., \& Marsden, M. E. (1999). Stress and Substance Use Among Military Women and Men. The American Journal of Drug and Alcohol Abuse, 25(2), 239-256. 
Bray, R. M., Hourani, L. L., \& Rae, K. L., et al. (2002) Department of Defense survey of health-related behaviors among military personnel. Research Triangle Park, NC, Research Triangle Institute, 2004.

Bray, R. M., \& Hourani, L. L. (2007). Substance use trends among active duty military personnel: findings from the United States Department of Defense Health Related Behavior Surveys, 1980-2005. Addiction, 102(7), 1092-1101.

Bray R. M., Pemberton M. R., Hourani L. L., Witt M., Olmsted K. L., Brown J. M., Weimer B., Lance M. E., Marsden M. E., \& Scheffler S. (2009). Department of Defense Survey of Health-Related Behaviors among Active Duty Military Personnel. Research Triangle Park, NC: RTI International.

Brown, M. C., Creel, A. H., Engel, C. C., Herrell, R. K., \& Hoge, C.W. (2011) Factors associated with interest in receiving help for mental health problems in combat veterans returning from deployment to Iraq. Journal of Nervous and Mental Disease, 199(10), 797-801.

Bucher, J. (2011). General Issue (G.I.) Strain: Applying Strain Theory to Military Offending. Deviant Behavior, 32, 846-875.

Buchanan, D. R. (1992). "A social history of American drug use." The Journal of Drug Issues, 22(1), 31-51. 
Burnett-Zeigler, I., Ilgen, M., Valenstein, M., Zivin, K., Blow, A. Duffy, S., \& Chermack, S. (2011). Prevalence and correlates of alcohol misuse among returning Afghanistan and Iraq veterans. Addictive Behaviors, 36(8), 801-807.

Byers, A. L., \& Yaffe, K. (2014). Depression and dementias among military veterans. Alzheimers \& Dementia, 10, S166-S173.

Calhoun, P. S., Elter, J. R., Jones, E. R., Kudler, H., \& Straits-Troster, K. (2008). Hazardous alcohol use and receipt of risk-reduction counseling among U.S. veterans of the wars in Iraq and Afghanistan. Journal of Clinical Psychiatry, 69(11), 1686-1693.

Calhoun, P. S., Schry, A. R., Wagner, H. R., Kimbrel, N. A., Dennis, P., McDonald, S. D., ... Straits-Troster, K. (2016). The Prevalence of Binge Drinking and Receipt of Provider Drinking Advice among U.S. Veterans with Military Service in Iraq or Afghanistan. The American Journal of Drug and Alcohol Abuse, 42(3), 269-278.

Campbell, T.L., Byrne, B.M., \& Baron, P. (1992). Gender Differences in the Expression of Depressive Symptoms in Early Adolescents. Journal of Early Adolescence, 12(3), 326-338.

Centers for Disease Control and Prevention (2019). Binge Drinking. Retrieved from https://www.cdc.gov/alcohol/fact-sheets/binge-drinking.htm 
Chang, B. H., \& Sommers, E. (2014). Acupuncture and relaxation response for craving and anxiety reduction among military veterans in recovery from substance use disorder. American Journal of Addiction, 23(2), 129-136.

Ciarleglio, M. M., Aslan, M., Proctor S. P., Concato, J. Ko, J. Kaiser, A. P., \& Vasterling, J. J., (2018). Associations of Stress Exposure and Social Support with Long Term Mental Health Outcomes Among U.S. Iraq War Veterans. Behavioral Therapy, 49(5), 653-667.

Cloward, R. (1959). Illegitimate Means, Anomie, and Deviant Behavior. American Sociological Review, 24(2), 164-176.

Cloward, R. \& Ohlin, L. (1960). Delinquency and Opportunity: A Theory of Delinquent Gangs. Glencoe, IL: Free Press.

Cooper, A. E., Corrigan, P. W., \& Watson, A. C. (2003). Mental illness stigma and care seeking. Journal of Nervous and Mental Disease, 191(5), 339-341.

Courtwright, D. (2001). Dark Paradise: A History of Opiate Addiction in America. Cambridge: Harvard University Press.

Cucciare, M. A., Simpson, T., Hoggatt, K. J., Gifford, E., \& Timko, C. (2013). Substance use among women veterans: Epidemiology to evidence-based treatment. Journal of Addictive Diseases, 32(2), 119-139.

Davis, A. K., Bonar, E. E., Goldstick, J. E., Walton, M. A., Winters, J., \& Chermack, S. T.(2017). Binge-drinking and non-partner aggression are associated with 
gambling among Veterans with recent substance use in VA outpatient treatment. Addictive Behaviors, 74, 27-32.

DoD. Directive 1010.4: Drug and alcohol abuse by DoD personnel. Washington, DC: DoD; 1997.

Dove, M. B., \& Joseph, H. J. (2007). Sociodemographic profile of women entering a military substance use disorder treatment center. Military Medicine, 172(3), 283 287.

Durkheim, E. [1893] 1933.The division of labor in society. Translated by George Simpson. New York: Free Press

Durkheim, E. (1897/1951). Suicide: A study in sociology. Glencoe, III: Free Press.

Erickson, D. J., Wolfe, J., King, D. W., King, L. A., \& Sharkansky, E. J. (2001). Posttraumatic stress disorder and depression symptomatology in a sample of Gulf War Veterans: a prospective analysis. Journal of Consulting Clinical Psychology, 69(1), 42-49.

Federman, E. B., Bray, R. M., \& Kroutil, L. A. (2000). Relationships Between Substance Use and Recent Deployments Among Women and Men in the Military. Military Psychology, 12(3), 205-220.

Fischer, H. (2015). A Guide to U.S. Military Causality Statistics: Operation Freedom's Sentinel, Operation Inherent Resolve, Operation New Dawn, Operation Iraqi 
Freedom, and Operation Enduring Freedom. Congressional Research Service. Retrieved from https://fas.org/sgp/crs/natsec/RS22452.pdf

Frank, C., Zamorski, M. A., Lee, J. E., \& Colman, I. (2018). Deployment-related trauma and post-traumatic stress disorder: Does gender matter? European Journal of Psychotraumatology, 9(1), 1-10.

Friedman, M. J., Schnurr, P. P., \& McDonagh-Coyle, A. (1994). Post-traumatic stress disorder in the military veteran. Psychiatric Clinics of North America, 17(2), 265 277.

Fuehrlein, B. S., Mota, N., Arias, A. J., Trevisan, L. A., Kachadour, L. K., Krystal, J. H., ...Pietrzak, R. H. (2016). The burden of alcohol use disorder in US military veterans: results from the National health and Resilience in Veterans Study. Addiction, 111(1), 1786-1794.

Gamache, G., Rosenheck, R., \& Tessler, R. (2003). Overrepresentation of Women Veterans Among Homeless Women. American Journal of Public Health, 93(7), $1132-1136$.

G. D. Garson. (n.d.). "Logistic Regression”. Retrieved from http://faculty.chass.ncsu.edu/garson/PA765/logistic.htm\#sigtests (2011).

Gibbs, D. A., Martin, S. L., Kupper, L. L., \& Johnson, R. E. (2007). Child maltreatment in enlisted soldiers' families during combat-related deployments. Journal of the American Medical Association, 298(5), 528- 535. 
Gibbs, D. A., \& Olmsted, K. L., (2011). Preliminary Examination of the Confidential Alcohol Treatment and Education Program. Military Psychology, 23, 97-111.

Goldstein, L. A., Dinh, J., Donalson, R., Hebenstreit, C. L., \& Mageun, S. (2017). Impact of military trauma exposures on posttraumatic stress and depression in female veterans. Psychiatry Research, 249, 281-285.

Goldzweig, C. L., Balekain, T. M., Rolon, C., Yano, E. M., \& Shekelle, P. G. (2006). The State of Women Veterans' Health Research. Results of a Systematic Review. Journal of General Internal Medicine, 21(3), 82-92.

Golub A, Vazan P, Bennett, A. S, \& Liberty, H. J. (2013). Unmet need for treatment of] substance use disorders and serious psychological distress among veterans: A nationwide analysis using the NSDUH. Military Medicine, 178(1), 107-114.

Golub, A., \& Bennett, A. S. (2013). Prescription Opioid Initiation, Correlates, and Consequences Among a Sample of OEF/OIF Military Personnel. Substance Use and Misuse, 48(10), 811-820.

Golub, A. \& Bennett, A. S. (2013). Introduction to the Special Issue: Drugs, Wars, Military Personnel, and Veterans. Substance Use and Misuse, 48(10), 1-6.

Green, K. J., Hunter, C. M., Bray, R. M., Pemberton, M., \& Williams, J. (2008). Peer and role model influences for cigarette smoking in a young adult military population. Nicotine \& Tobacco Research, 10(10), 1533-1541. 
Grucza, R. A., Sher, K. J., Kerr, W. C., Krauss, M. J., Lui, C. K., McDowell, Y. E., .. \& Bierut, L. J. (2018). Trends in Adult Alcohol Use and Binge Drinking in the Early 21st-Century United States: A Meta-Analysis of 6 National Survey Series. Alcoholism, 42(10), 1939-1950.

Hammarlund, R., Crapanzano, K. A., Luce, L., Mulligan, L., \& Ward, K. M. (2018). Review of the effects of self-stigma and perceived social stigma on the treatment seeking decisions of individuals with drug- and alcohol-use disorders. Substance Abuse Rehabilitation, 9, 115-136.

Hanwella R, de Silva V. A., \& Jayasekera, N. E. (2012). Alcohol use in a military population deployed in combat areas: a cross sectional study. Substance Abuse Treatment, Prevention, and Policy, 7(24), 1-7.

Harris, A. H., Oliva, E., Bowe, T., Humphreys, K. N., Kivlahan, D. R., \& Trafton, J. A. (2012). Pharmacotherapy of Alcohol Use Disorders by the Veterans Health Administration: Patterns of Receipt and Persistence. Psychostric Services, 63(7), 679-685).

Hermens, D. F., Lee, R. S., De Regt, T., Lagopoulos, J., Naismith, S. L., Scott, E. M., Hickie, I. B. (2010). Neuropsychological functioning is compromised in binge drinking young adults with depression. Psychiatry Research, 210, 256-62. 
Hoggatt, K.J., Jamison, A. L., Lehavot, K., Cucciare, M. A., Timko, C. \& Simpson, T. L. (2014). Alcohol and Drug Misuse, Abuse, and Dependence in Women Veterans. Epidemiologic Reviews, 37, 23-37.

Hoopsick, R. A., Fillo, J., Vest, B. M., Homish, L. D., \& Homish, G.G. (2017). Substance use and dependence among current reserve and former military members: Cross sectional findings from the National Survey on Drug Use and Health, 2010-2014. Journal of Addictive Diseases, 36(4), 243-251.

Hoopsick, R. A., Homish, D. L., Vest, B. M., Homish, G.G. (2018). Alcohol use among never deployed U.S. Army Reserve and National Guard Soldiers: The effects of nondeployment Emotions and Sex. Alcoholism: Clinical and Experimental Research, 42(12), 2413-2422.

Jacobson, I. G., Ryan, M. A., Hooper, T. I., Smith, T. C., Amoroso, P. J., Boyko, E. J., Gackstetter, G. D., Wells, T. S., \& Bell, N. (2008). Alcohol Use and Alcohol Related Problems Before and After Military Combat Deployment. Journal of American Medical Association, Vol, 300, No. 6., pp. 663-675.

Jacobson, I. G., Donoho, C. J., Crum-Cianflone, N. F., \& Maguen, S. (2015). Longitudinal assessment of gender differences in the development of PTSD among US military personnel deployed in support of the operations in Iraq and Afghanistan. Journal of Psychiatric Research, 68, 30-36. 
Jensen, P. S., Grogan, D., Xenakis, S. N., \& Bain, M. W. (1989). Father absence: Effects on child and maternal psychopathology. Journal of the American Academy of Child and Adolescent Psychiatry, 28(2), 171-175.

Killgore, W. D., Cotting, D. I., Thomas, J. L., Cox, A. L., McGurk, D., \& Vo, A. H. (2008).Post-combat invincibility: Violent combat experiences are associated with increased risk-taking propensity following deployment. Journal of Psychiatric Research, 42(13), 1112-1121.

Kracen, A. C., Mastnak, J. M., Loaiza, K. A., \& Matthieu, M. M. (2013). Group Therapy Among OEF/OIF Veterans: Treatment Barriers and Preferences. Military Medicine, 178, 146-149.

Lande, R. G. (2014). Stress in service members. The Psychiatrics clinic of North America, 37(4), 547-560.

Lande, R. G., Marin, B. A., Chang, A. S. \& Lande, G. R. (2008). Survey of alcohol use in the U.S. Army. Journal of Addictive Diseases, 27(3), 115-121.

Lester P, Peterson K, Reeves J et al. (2010). The Long War and Parental Combat Deployment: Effects on Military Children and At-Home Spouses. Journal of American Academy of Child Adolescent Psychiatry, 49(4), 310-320.

Lingford-Hughes, A. R., Welch, S. \& Nutt, D. (2004). Evidence-based guidelines for the pharmacological management of substance issues, addiction and comorbidity: 
Recommendations from the British Association for Psychopharmacology. Journal of Psychopharmacology, 18(3), 293-335.

Litman, J. A. (2006). The COPE inventory: Dimensionality and relationships with approach-and-avoidance-motives and positive and negative traits. Personality and Individual Differences, 41(2), 273-284.

Luxton, D. D., Pruitt, L. D., O’Brien, K., Stanfull, K., Jenkins-Guarnieri, M. A., Johnson, K. Wagner, A., Thomas, E., \& Gahm G. A. (2014). Design and methodology of randomized clinical trial of home-based telemental health treatment for U.S. Military personnel and veterans with depression. Contemporary Clinical Trials, $38,134-144$.

MacLean, A. (2010). The Thing They Carry: Combat, Disability, and Unemployment among U.S. Men. American Sociological Review, 1-23.

Maguen, S., Luxton, D. D., Skopp, N, A. Madden, E. (2012). Gender differences in traumatic experiences and mental health in active duty soldiers redeployed from Iraq and Afghanistan. Journal of Psychiatric Research, 46(3), 311-316.

Martinez, M. N., \& Bartholomew, M. J. (2017). What Does It "Mean"? A Review of Interpreting and Calculating Different Types of Means and Standard Deviations. Pharmaceutics, 9(14), 1-23. 
Mattiko, M. K., Olmsted, K. L., Brown, J. M., \& Bray, R. M. (2011). Alcohol use and negative consequences among active duty military personnel. Addictive Behaviors, 36(6), 608-614.

McDevitt-Murphy, M. E., Williams, J. L., Murphy, J. G., Monahan, C. J., \& Bracken Minor, K. L. (2010). Brief Intervention to Reduce Hazardous Drinking and Enhancing Coping Among OEF/OIF/OND Veterans. Professional Psychology: Research and Practice, 46(2), 83-89.

McKenzie D. P., McFarlane A. C., Creamer M., Ikin J. F., Forbes A. B, Kelsall H. L., ... Sim, M. R. (2006). Hazardous or harmful alcohol use in Royal Australian Navy veterans of the 1991 Gulf War: identification of high-risk subgroups. Addictive Behavior, 31(9), 1683-1694.

Merton, R. K. (1938). Social Structure and Anomie. American Sociological Review, 3(5), $672-682$.

Mental Health Advisory Team IV (2006). Operation Iraqi Freedom 05-07. Office of the Surgeon Multinational Force Iraq and Office of the Surgeon General United States Army Medical Command.

Miedzian, M. (1991). Boys will be boys: Breaking the link between masculinity and violence. New York, NY: Anchor Books, Doubleday. 
Miller, S. M., Pedersen, E. R., \& Marshall, G. N. (2017). Combat Experience and Problem Drinking in Veterans: Exploring the roles of PTSD, coping motives, and perceived stigma. Addicted Behavior, 66, 90-95.

Morin, R. (2011). The difficult transition from military to civilian life. Washington, DC: Pew Research Center.

Mukaka, M. M. (2012). A guide to appropriate use of Correlation coefficient in medical research. Malawi Medical Journal, 24(3), 69-71.

Najavits, L. M. (2002). Clinicians' views on treating posttraumatic stress disorder and substance use disorder. Journal of Substance Abuse Treatment, 22(2), 79-85.

National Institute of Alcohol Abuse and Alcoholism. NIAA council approves definition of binge drinking. NIAAA Newsletter. 2004;3:3.

Sharbafchi, M. R. \& Heydari, M. (2017). Management of Substance Use Disorder in Military Services: A Comprehensive Approach. Advanced Biomedical Research, 6(122), 1-64.

Sloan, D. M., \& Beck, J. G. (2016). Group Treatment for PTSD. PTSD Research Quarterly, 27(2), 2-9.

Sperandei, S. (2014). Understanding logistic regression analysis. Biochemical Medicine, 24(1), 12-18.

Substance Abuse and Mental Health Services Administration, Results from the 2002 2017 National Survey on Drug Use and Health: Summary of National Findings, 
NSDUH Series H-48, HHS Publication No. (SMA) 14-4863. Rockville, MD: Substance Abuse and Mental Health Services Administration, 2014. O’brien, R. M. (2007). A Caution Regarding Rules of Thumb for Variance Inflation Factors. Quality \& Quantity, 41, 673-690.

Olenick, M., Flowers, M., \& Diaz, V. J. (2015). US veterans and their unique issues: enhancing health care professional awareness. Advances in Medical Education and Practice, 6, 635-639.

Osilla, K. C., Trail, T. E., Pedersen, E. R., Gore, K. L., \& Tolpadi, A. (2017). Efficacy of a Web Based Intervention for Concerned Spouses of Service Members and Veterans with Alcohol Misuse. Journal of Marital and Family Therapy, 44(2), 292-306.

Perl, L. (2011). Veterans and Homelessness. Congressional Research Service; Washington, DC.

Pflanz, S. E., \& Ogle, A. D. (2006). Job stress, depression, work performance, and perceptions of supervisors in military personnel. Military Medicine, 171(9), 861 865.

Pieper, B. (2004). Practice Strategies: TRICARE. American Optometric Association, 75(2), 123-126.

Polusny, M., Kehle, S., Nelson, N., Erbes, C., Arbisi, P., \& Thuras, P. (2011). Longitudinal effects of mild traumatic brain injury and posttraumatic stress 
disorder comorbidity on post deployment outcomes in national guard soldiers deployed to Iraq. Archives of General Psychiatry, 68(1), 79-89.

Pruitt, L. D., Luxton, D. D. \& Shore, P. (2014). Additional clinical benefits of home based telemental health treatment. Professional Psychology: Research and Practice, 45(5), 340-346.

Rasmussen, N. (2011). Medical Science and the Military: The Allies use of Amphetamines during World War II. The Journal of Interdisciplinary History, 42(2), 205-233.

Robins, L. N., Helzer, J. E., Davis, D. H. (1975). Narcotic use in Southeast Asia and afterword. Archives of General Psychiatry, 32, 955-961.

Robinson, J.T., \& Kidd, G. B. (1951). Impressions on the Use of "Antabuse" in the Treatment of Alcoholism in the Army. The Journal of Royal Army Medical Corps, 97(5), 363- 371.

Room, R., Babor, T., \& Rehm, J. (2005). Alcohol and Public Health. Lancet, 365, 519 530.

Rosen, L. N., \& Teitelbaum, J. M. (1993). Children's reactions to the Desert Storm deployment: Initial findings from a survey of Army families. Military Medicine, 158(7), 465-459.

Rosenberg, M. (1990). Reflexivity and emotions. Social Psychology Quarterly, 53, 3-12. 
Rothberg, J. M., Koshes, R. J., Shanahan, J., \& Christman, J. (1994). Desert Shield deployment and social problems on a U.S. Army combat support post. Military Medicine, 159, 246-248.

Sacks, J. J., Gonzales, K. R., Bouchery, E. E., Tomedi, L.E., Brewer, R. D. (2015). 2010 National and state costs of excessive alcohol consumption. American Journal of Preventative Medicine, 49(5), 73-79.

Schuman D. L., Slone, N. C. Reese, R. J. \& Duncan, B. (2014). Efficacy of Client feedback in group psychotherapy with soldiers referred for substance abuse treatment. Psychotherapy Research, 25(4), 396-407.

Schumm J. A. \& Chard, K. M. (2012) Alcohol and stress in the military. Alcohol Research: Current Reviews, 34, 401-407.

Sharbafchi, M. R., Heydari, M. (2017). Management of Substance Use Disorder in Military: A Comprehensive Approach. Advanced Biomedical Research, 6, 122

Sheffler, J. L., Rushing, N. C., Stanley, I. H., \& Sachs-Ericsson, N. J. (2016). The longterm impact of combat exposure on health, interpersonal, and economic domains of functioning. Aging \& Mental Health, 20(11), 1202-1212.

Shen, Y. C,, Arkes, J., \& Williams, T. V. (2012). Effects of Iraq/Afghanistan deployments on major depression and substance use disorder: analysis of active duty personnel in the US military. American Journal of Public Health, 102(1), 8087. 
Sigfusdottir, I. D., Kristjansson, A. L., \& Agnew, R. (2012). A comparative analysis of general strain theory. Journal of Criminal Justice, 40, 117-127.

Sinha, R. (2008). Chronic Stress, Drug Use, and Vulnerability to Addiction. Annals of the New York Academy of Sciences, 1141(1), 105-130.

Springfield, L. (1902). The Tobacco War in Great Britain. The North American Review, 174(547), 820-832.

Stahre, M. A., Brewer R. D., Fonseca V. P., \& Naimi T. S. (2009). Binge drinking among U.S. active-duty military personnel. American Journal of Preventative Medicine, $36,208-217$.

Stanton, D. M. (2009). Drugs, Vietnam, and the Vietnam Veteran: An Overview. The American Journal of Drug and Alcohol Abuse, 3(4), 557-570.

Stecker, T., Fortney, J. C., Hamilton, F., \& Ajzen, I. (2007). An assessment of beliefs about mental health care among veterans who served in Iraq. Psychiatric Services, 58(10), 1358-1361.

Stinchfield, R., Owen, P. L., \& Winters, K. C. (1994). Group therapy for substance abuse: A review of the empirical research. In A. Fuhriman and G. M. Burlingame (Eds.), Handbook of group psychotherapy: An empirical and clinical synthesis (458-488). New York: Wiley.

Substance Abuse and Mental Health Services Administration. Substance Abuse Treatment: Addressing the Specific Needs of Women. Treatment Improvement 
Protocol (TIP) Series, No. 51. HHS Publication No. (SMA) 13-4426. Rockville, MD: Substance Abuse and Mental Health Services Administration, 2009.

Substance Abuse and Mental Health Services Administration. Mental Health and Substance Use Disorder. (2019). Retrieved from https://www.samhsa.gov/find help/disorders.

Substance Abuse and Mental Health Services Administration. Medication and Counseling Treatment. (2019). Retrieved from https://www.samhsa.gov/medication-assistedtreatment/treatment.

Taylor, J. E., Haddock, K. C., Poston, W. S., \& Talcott, W. G. (2007). Relationship between Patterns of Alcohol Use and Negative Alcohol-Related Outcomes among U.S. Air Force Recruits. Military Medicine, 172(4), 379-382.

Thabane, L., Mbuagbaw, L., Zhang, S., Samann, Z., Marcucci, M., Ye, C., Thabane, M.,...\& Goldsmith, C. H. (2013). A tutorial on sensitivity analyses in clinical trials: the what, why, when and how. Medical Research Methodology, 13, 1-12.

Thomas, J. L., Wilk, J. E., Riviere, L. A., McGurk, D., Castro, C. A., \& Hoge, C. W. (2010).Prevalence of Mental Health Problems and Functional Impairment Among Active Component and National Guard Soldiers 3- and 12-months Following Combat in Iraq. Archives in General Psychiatry, 67(6), 614-623.

Tiffany, S. T., \& Carter, B. L. (1998). Is craving the source of compulsive drug use? Journal of Psychopharmacology, 12(1), 23-30. 
Trautmann, S., Schonfeld, S., Behrendt, S., Holfer, M. Zimmerman, P., \& Wittchan, H. (2014). Substance use and substance use disorders in recently deployed and never deployed soldiers. Drug and Alcohol Dependence, 134, 128-135.

Ursano, R. J., Wang, J., Ramsawh, H., Russell, D., Benfer, N., Gifford, R. K.,... \& Fullerton, C. S. (2016). Post-Traumatic Stress Disorder, Depression, and Binge Drinking in the Reserves Component of the U.S. Armed Forces. Military Medicine, 181(10), 1287-1983.

U.S. Department of Veteran Affairs. (2013). Study and Report on Making Per Deim Payments to Providers for Homeless Veterans.

U.S. Department of Veteran Affairs. (2019). Treatment of Co-Occuring PTSD and Substance Use Disorder in VA. Retrieved from https://www.ptsd.va.gov/professional/treat/cooccurring/tx_sud_va.asp

Valenstein, M., Gorman, L., Blow, A. J., Ganoczy, D., Walters, H., Kees, M.,... Dalack, G. W. (2014). Reported barriers to mental health care in three samples of U.S. Army National Guard soldiers at three time points. Journal of Traumatic Stress, 27(4), 406-14.

Vatcheva, K. P., Lee, M., McCormick, J. B., \& Rahbar, M.H. (2016). Multicollinearity in Regression Analysis Conducted in Epidemiologic Studies. Epidemiology, 6(2), 227, 1-20. 
Vayalapalli, S., Fareed, A., Byrd-Sellers, J., Stout, S., Casarella, J., \& Drexler, K. (2013). Predictors of Substance Abuse Treatment Outcome in Hospitalized Veterans. American Journal on Addictions, 22(4), 358-365.

Veterans Resource Center (2019). Case Management. Retrieved from https://www.vetsresource.org/what-we-do/case-management/

Vogt, D., Vaughn, R., Glickman, M.E., Schultz, M., Drainoni, M. L., Elwy, R., \& Eisen, S. (2011). Gender differences in combat-related stressors and their association with post deployment mental health in a nationally representative sample of U.S. OEF/OIF veterans. Journal of Abnormal Psychology, 120(4), 797-806.

Washington, D. L., Yano, E. M., McGuire, J., Hinges, V., Lee, M., \& Gelberg, L. (2010). Risk factors for homelessness among women Veterans. Journal of Health Care for the Poor and Underserved, 21, 82-91.

Wheaton B. (1990). Life transitions, role histories, and mental health. American Sociological Review, 55(2), 209-223.

White, R., Barber, C., Azrael, D., Mukamal, K. J., \& Miller, M. (2011). History of Military service and the risk of suicidal ideation: findings from the 2008 national survey on drug use and health. Suicide and life-threatening behavior, 41(5), 554 561. 
Whiteman, S. D., \& Barry, A. E. (2011). A comparative analysis of student service member/veteran and civilian student drinking motives. Journal of Student Affairs Research Practice, 48(3), 297-313.

Xiong, H., Zhang, X., Zhang, Y., Ma, F., \& Li, Y. L. (2005). An investigation of the prevalence of depressive symptoms in soldiers during military training. Preventative Medicine, 41, 642-645.

Zogas, A. (2017). US Military Veterans' Difficult Transitions Back to Civilian Life and the VA's Response. Costs of War. Watson Institute International and Public Affairs, 1-14. 
CURRICULUM VITAE

\author{
Emily A. Hayden \\ Campbellsville University \\ Department of Criminal Justice \\ Campbellsville, KY \\ eahayden@campbellvsille.edu
}

\title{
ACADEMIC EMPLOYMENT
}

2019- Present

Campbellsville University

Assistant Professor of Criminal Justice

EDUCATION

2015-2020

2013-2015

2009-2013
University of Louisville

$\mathrm{PhD}$ Criminal Justice

Eastern Kentucky University

M.S. Justice Studies

Kentucky Wesleyan College

B.A. Criminal Justice, Criminology and Law
Campbellsville, KY

Louisville, KY

Richmond, KY

Owensboro, KY

\section{ACADEMIC POSITIONS AND AFEILIATIONS}

2018- 2019

(funded)

2017- 2018

(funded)

2016-2017

(funded)

2013-2015
Graduate Teaching Assistant

University of Louisville, Criminal Justice

Graduate Research Assistant

University of Louisville, Criminal Justice

Graduate Research Assistant, NIJ Grant

University of Louisville, Criminal Justice

Graduate Research Assistant
Louisville, Ky

Louisville, Ky

Louisville, KY

Richmond, KY 
(funded) $\quad$ Eastern Kentucky University, School of Justice Studies

\section{PROFESSIONAL WORK EXPERIENCE}

2016-2016

2016-2016

2011-2013
NOA Counseling

Moral Reconation Therapy Facilitator

United American Security

Security Officer, Glenmore Distillery

Daviess County Detention Center

Deputy, Non-Hazardous/Administrative
Louisville, KY

Owensboro, KY

Owensboro, KY

\section{RESEARCH EXPERIENCE}

Principle Investigator, for the project: Relationship typologies and female offending: $a$ life course analysis. 08/15/2012, IRB approval. KWC34AJ

Research Assistant, for the project: Training evaluation study. National Institute of Corrections. 08/15/2014, Fayette County Jail, Lexington Kentucky

Research Assistant, for the NIJ project: Understanding the Adoption, Function, and Consequences of School Resource Officer Use in Understudied Settings, 01/20/2017 University of Louisville.

Co-Investigator, for the project: Habitus of the Academy. IRB approval. University of Louisville.

Co- Investigator, for the project: The State of Authorship in Criminology. IRB Approval. University of Louisville.

\section{TEACHING EXPERIENCE}

CJ 232 Juvenile Justice in America

CJ 332 Juvenile Delinquency

CJ 334 Introduction to Criminal Law

CJ 415 Family Violence 
CJ 426 Probation and Parole

CJ 400 Criminological Theory

CJ 450 Victimology

\section{CONFERENCE PRESENTATIONS}

Presented

2018 American Society of Criminology, Co-presenter

Atlanta, GA

TITLE: Peer pressure and substance use: A trajectory analysis using Primary Socialization Theory

2014 Criminal Justice and Security in Central and Eastern Europe,

Ljubljana, Slovenia

Individual Presenter

TITLE: Increasing female criminality in Slovenia: A life-course analysis

2014 American Society of Criminology, Co-presenter

San Francisco, CA

TITLE: Intimate Partners in Crime: Utilizing Life Course Analysis to Examine Female

Involvement in Criminal Activity While Cohabitating

2014 American Society of Criminology, Co-presenter

San Francisco, CA

TITLE: “Peeragogy” in Criminal Justice Education: Utilizing Applied Research in a Graduate

Statistics Classroom

2014 American Society of Criminology, Individual Presenter

San Francisco, CA

TITLE: The Relationship between Perceived and Reported Violence and Conflict in a Jail

2013 American Society of Criminology, Individual Presenter,

Atlanta GA

TITLE: Female Offending: Effects of Relationship Stability and cohabitation

2012 American Society of Criminology, Individual Presenter,

Chicago, IL

TITLE: Relationship typologies and female offending: a life course analysis

2012 Scholars Day: Criminal Justice Research Center Owensboro, KY

Attended

2013 International Crime Media and Popular Culture Studies Conference.

Terra Haute, IN

2012 Kentucky Conference on Human Trafficking.

Georgetown, KY

\section{Awarded Travel Grants/Funds for Academic Advancement}

2014 Eastern Kentucky University (Slovenia)

2013 Eastern Kentucky University

2013 Kentucky Wesleyan College
Comparative and International Crime

American Society of Criminology

Leadership through Sailing

114 
(Virgin Islands, U.S.)

2012 Kentucky Wesleyan College American Society of Criminology

(Chicago, IL)

\section{Professional Experience}

- Peer Mentoring Educator Pilot Program, Eastern Kentucky University's College of Education: EDO 100 (Academic Orientation)

- Principle Investigator, for the project: Relationship typologies and female offending: a life course analysis. 08/15/2012, IRB approval. KWC34AJ

- Research Assistant, for the project: Training evaluation study. National Institute of Corrections. Fayette County Jail, Lexington Kentucky

- Deputized Sherriff at the Daviess County Detention Center

- Correctional Training: 80 Hours field training, 40 hours non-hazardous

- Criminal Justice Practicum: Spring 2012, Fall 2012, Spring 2013

- Criminal Justice Independent Study:

Qualitative Survey Construction: Interview \& Questionnaires

- Criminal Justice Student Association, KWC Secretary

- Graduate Student Association, EKU Social Chair

- Southern Poverty Law Center, EKU Secretary

\section{Publications}

- Lockdown Nation: An Encyclopedia of Controversies and Trends in American Prisons: Health Promotion in Prison Settings.

- Journal of Criminal Justice Education: The State of Authorship in Criminology: Perceptions of Right and Order among Elite Criminologists 